\title{
Firm Survival through Semi-Exits: The Case of Indian Registered Manufacturing
}

\section{Priyambada Gupta}

Assistant Professor at Sri Guru Nanak Dev Khalsa College, University of Delhi, Department of Economics, India.

Email:privambadagupta96@gmail.com Tel:+918860368802

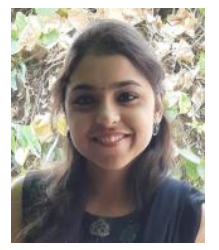

\begin{abstract}
The paper examines the extent to which product line change as a strategy improves the performance of firms across two manufacturing sectors over a period from 2008-2017. Durability and technology are the two dimensions chosen to identify the sectors. Hence, the paper studies electronic industry and food industry firms as the former are science-based, high-tech firms, whereas, the latter is a traditional manufacturing according to the Pavitt's taxonomy. Additionally, food products are known to be less durable than the electronic and electrical products. The paper analyzes the data using a cross-section difference-in-differences estimation to study the difference in average performance since the strategy is not an exogenous treatment but relies on firm-specific characteristics. In Appendix 2 results from a hypothetical case is presented in which it shows how the average performance across the two sectors adopting the strategy differs had the strategy been completely exogenous. The results hint towards an overwhelming improvement in the performance for electronic industry firms showing a change in product line as compared to food industry firms not adopting the strategy. Even though it is vital in enhancing the efficiency in firms which is shown both theoretically and empirically still only a few firms adopt the strategy in the Indian market. The paper tries to find reasons for the same by using certain case studies and see how product line change may not be an ideal strategy to undertake despite its role in allocating resources efficiently.
\end{abstract}

Keywords: Industrial organization, Firm survival, Product line change, Durable and technology intensive firms, Difference-in differences estimation method, RCT, Propensity score matching.

JEL Classification: Lo0; L63; L66.

Citation | Priyambada Gupta (2019). Firm Survival through SemiExits: The Case of Indian Registered Manufacturing. Asian Journal of Economics and Empirical Research, 6(2): 148-168. History:

Received: 8 August 2019

Revised: 12 September 2019

Accepted: 16 October 2019

Published: 2 December 2019

Licensed: This work is licensed under a Creative Commons

Attribution 3.0 License (oc)

Publisher: Asian Online Journal Publishing Group
Funding: This study received no specific financial support.

Competing Interests: The author declares that there are no conflicts of

interests regarding the publication of this paper.
Transparency: The author confirms that the manuscript is an honest, Transparency: The author confirms that the manuscript is an honest,
accurate, and transparent account of the study was reported; that no vital accurate, and transparent account of the study was reported; that no vital
features of the study have been omitted; and that any discrepancies from the features of the study have been omitted;
study as planned have been explained.

Ethical: This study follows all ethical practices during writing.

\section{Contents}

1. Introduction

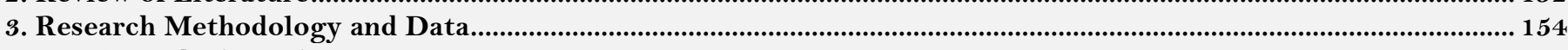

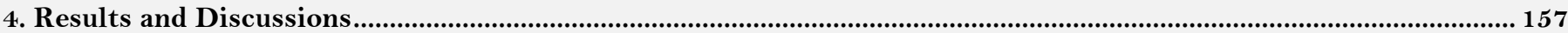

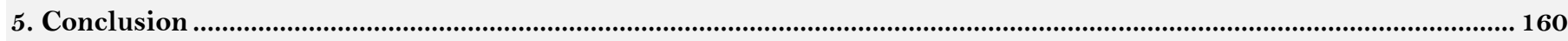

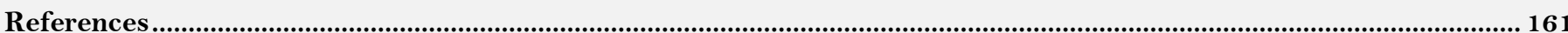




\section{Contribution of this paper to the literature}

The paper contributes to the existing literature by examining the extent to which product line change as a strategy improves the performance of firms across two manufacturing sectors over a period from 20082017 in India.

\section{Introduction}

The manufacturing sector is one of the most crucial drivers of economic growth for any economy, and henceforth the development of a high-quality manufacturing sector has been the strategy of rich nations over the last several hundred years to develop national wealth and power. It has been the fuel for the growth of the five largest economies of the world, namely the US, China, Japan, Germany \& United Kingdom. It leads to rapid modernization and provided millions of skilled and unskilled jobs directly or indirectly. It has played an indispensable role in moving millions of workers from the agriculture sector to the industries in the East Asian countries, thus improving the living standards of the population.

Manufacturing plays a fundamental role in the Indian economy. The Gross Value Added (GVA) for the manufacturing sector at constant prices grew at a CAGR of 4.34 percent during the fiscal year 2012 and 2018 (Annual national income published by the GOI). Value-added as a percentage of GDP by the manufacturing sector was reported at 15 percent in 2017 (World Bank data). Manufacturing plays a crucial role in job creation. The sector added an estimated 89,000 jobs in the second quarter of 2017-18 in India (Labour Bureau's Quarterly Report on Employment Scenario) and absorbed 12 percent of the labour force.

It is well analyzed in the literature that India's growth has been fueled by the service sector which has shown the characteristic of 'jobless growth.' With over 5 million new entrants in the labour market each year (World Development Indicators), the focus of policymakers is now shifting towards the manufacturing sector which has a high potential to absorb the increasing labour force. The government has instituted National Manufacturing Policy in 2011 which plans to boost manufacturing by raising its contribution to GDP to 25 percent and create 100 million new jobs by 2022. According to this policy, every job created in manufacturing creates two-three jobs additionally in the related activities. Prime Minister Narendra Modi led government launched 'Make in India' campaign in September 2014 to transform India into a manufacturing hub.

For the initiatives of the government to boost an environment to enhance business and create jobs to be successful, the survival of the firms in the industry plays a pivotal role. There are problems if a firm is forced to shut operations before its natural life cycle which includes an introduction phase, growth, maturity and then finally a decline arising because of exhausted demand or competition. India's industrial activity has been highly regulated which has posed a constraint on its development. Liberalization policies were adopted in 1991, but India still ranks very low in terms of providing an enabling nature for its business environment and unnecessary regulatory burdens are imposed on businesses and investors even now.

\subsection{Firm Survival Strategies}

A change in the product line is one of the strategies for survival by firms facing tight competition from the rivals. This route to survive is not well studied in the literature. We call this kind of a change in product line a semi-exit, undertaken by firms for restructuring their operations and survive in the industry. In Joseph Schumpeter's Creative Destruction innovation is the force that sustained growth in the economy, entry by an innovative entrepreneur destroys the established firms, and the process continues when there is another breakthrough in technological innovation. There is a substantial gain in total output with this redistribution of production from low performing to the high performing firms within the industry. But these models do not consider the reallocation of the product lines within the firms in a multiproduct setup.

Various other restructuring strategies were adopted by the Indian private corporate sector. An important method of restructuring was in the form of Mergers and Acquisitions (M\&A). Some of India's most famous business groups like Tata, Birla, Goenka, Piramal, and Modi engaged in the acquisition of profitmaking companies in the 1980s. Section 72-A of the Income Tax Act was introduced which encouraged the merger of sick firms with healthy firms by offering tax and other fiscal benefits to the acquiring firm. Therefore, some M\&As were also undertaken for this purpose. The recent merger of Idea Cellular Ltd and Vodafone India Ltd can also be seen as a strategy for survival after the entry of Reliance Jio in 2016 disrupted the telecom sector in India.

Outsourcing can also help firms survive and remain viable, particularly during an economic crisis. Apart from services, manufacturing firms also outsource the production of some specific components, for example, automobile parts. A study by Kar and Dutta showed the evidence of outsourcing by approximately 70 percent of the India manufacturing firms and found that outsourcing unambiguously increase the productivity of the firms (Kar and Dutta, 2018).

Firms can also survive and thrive by a building nexus between the business and the political class and involving in rent-seeking activities called Crony Capitalism. Government helps the firms to survive by providing subsidies and trade protections, even if these efforts increase inefficiencies in the economy. On the other hand, the other strategies mentioned are self-selected conscious survival strategies by the firms which are not rent-seeking and enhance the efficiency by employing resources to their use. Insolvency and Bankruptcy code was passed in 2016, to make the process of doing business a little less cumbersome, it tries to minimize the time and cost in attaining liquidation. Bankruptcy is a complete exit by a firm from the industry.

Although M\&As have been a crucial element of corporate strategy all over the world for several decades, research has not been able to provide compelling evidence on whether they enhance efficiency. There is a growing debate on the effects of M\&As on firms on a global level (Bedi, 2010). Indian firms do not show much evidence of a large number of mergers and acquisitions. M\&A proposals could also end up under the scanner of competition regulators.

Outsourcing as a survival strategy is also debatable. It is done for various purposes like cost reduction, taking advantage of cheap labour or low taxes. Production typically gets outsourced to a contract manufacturer that produces goods under the label of another firm. The original company can gain in flexibility as it does not have to 
invest in capital if there is an increase in demand and can request the contract manufacturer for the increased quantity which has a higher production capacity.

The central theme of this thesis is to study the patterns of product line change as a survival strategy in the Indian manufacturing firms. Durability and technology are the two dimensions chosen to identify two different sectors and firms therein to study the strategy. Durable goods are the goods that last for a longer duration with no easy wear and tear, most importantly these goods give utility over a longer period rather than being utilized for one-time use. Industries differ in the degree of durability of the end product. For instance, industry manufacturing food products and beverages are less durable as compared to the industries producing textiles or basic metals. The second dimension is technology which keeps on changing and the firms producing such goods have to keep reinventing their products to survive the competition. We control for differences in the technological environment using Pavitt's taxonomy. Pavitt (1984) taxonomy helps to capture some fundamental differences in the characteristics of the innovation process such as its nature and direction of change that distinguish firms operating in different industrial sectors. It consists of four categories of industrial firms; supplier dominated, scale intensive, specialized suppliers, and science-based.

\subsection{Importance of Product Line Change for Durable Goods Industries}

Because of the feature of durability, the firms producing such goods create a self-created competition in addition to the outside competition. They foreclose the chunk of the market they have already served as the consumers keep these good for a longer duration depending upon the durability of that good. This feature changes the kind of competition these firms face and also their strategies to sustain it. Planned Obsolescence which artificially reduces the life of these good is one of the ill strategies used by the producers, but they face limitations in using this because of the outside competition and also it affects their reputation (Bulow, 1986). The firms producing such goods adopt excess momentum in product introduction as compared to excess inertia to revive the demand for their products in the market. They create a condition under which the consumers find the new product essential. Software which is introduced over time as a different version of the previous one can be seen as an example.

\subsection{Importance of Product Line Change for Technology Intensive Industries}

The one sure thing about innovation is, that it is about to change. Introduction of new products which use better technologies alter the existing patterns in the market. These patterns are evident in the daily market situations ${ }^{1}$. Technology opens up opportunities for a company to redeploy its assets and rethink its strategy. Technological innovation can lead to dramatic cost reduction which can significantly change the old rules of competition. Firms can add value to their products that will permit a change in competition on the basis of product differentiation. To cope up with changing environment firms to survive in the industry should transform their products to embody the new technology in them. We can claim that for such firms making changes in the products is quite essential. For instance, the electronics industry has an extensive scope of technological innovations. Firms in the industry producing mobile phones are launching newer versions of the mobile almost every year. These goods are being continuously replaced with latest and improved versions.

\subsection{Importance of Product Line Change as a Survival Strategy}

We will motivate this idea by using two case studies- first, that of Eastman Kodak Company which completely revolutionized how photography was done and the other of Intel Corporation which had a strategic business exit and survived. Durable goods industries cannot be isolated from the technological intensive industries as in these two examples both the goods are durables but differ in their technological intensity. Microprocessors can be considered to be more technological intensive as compared to film cameras.

1. Eastman Kodak Company founded by George Eastman and Henry Strong in 1882 was the biggest name in the photography industry. They started with being the king of the industry to being bankrupt in 2012; they still exist today but in a very different form. Before Kodak, taking a photograph was a tedious procedure and was mainly done by professionals. It was done using glass plates installed in the back of the camera on which light was focused through the lens. It had to be kept away from all the sources of light and treated with chemicals. The photographer had to carry a pile of glass plates while going out for capturing pictures (Leggat, 1995). Kodak's major advancement was the chemically coated film that replaced the delicate glass plates. Kodak rollfilm camera was made to become an integral part of one's life. Kodak Moment as they called became a synonym for a photograph. This was achieved through various ad campaigns which transformed the way people looked at photographs (Munir and Phillips, 2005). In 1976 they had an 85\% market share in cameras and 90\% market share in films.

By the 1990s there was a rise in digital cameras. In 1975 Steve Sasson, an engineer working for Kodak invented the first digital camera, they also received a patent for it. But the problem was they did not focus on the digital cameras enough (Anthony, 2016). In 2005 the leader in the digital market in the US was still Kodak, but this time their share was only $22.1 \%$ with significant competitors like Canon and Sony. They were reluctant to change their product line as they knew everything about films; they had created it and had more than 100 years of experience in it. Also, they made money through films rather than the sale of cameras. They ignored the fact that digital cameras are the future. Later cameras merged with mobile phones and rather than getting pictures printed people preferred posting it on the social media. Their market share fell considerably. They tried to make a switch to different products like printers, but it was not very successful as there were already established firms like hp. This led to their bankruptcy in 2012. They are now back but not in the same way as they were, their revenues are considerably low.

'Reliance Jio offered free HD voice services through VoLTE enabled handsets which should be connected to 4G networks. Entry of Jio shut wireless operations of small operators. like Aircel and Reliance communication. Bharti Airtel acquired Telenor and Tata Tele-services. Vodafone and Idea Cellular merged. The focus of companies has now shifted from the number of users to more data usage per SIM, as a strategy to survive. For instance, Airtel is boosting its offering by tying up with video platforms such as Amazon Prime, Netflix and ZEE5; whereas Jio is looking forward to producing in-house content Bhatia, J., 2016. Reliance jio: Predatory pricing or predatory behaviour? Economic and Political Weekly, $51(39)$. 
This story of Kodak hints at the fact that a miss in the understanding of product switching can lead to the downfall of a massively profitable venture. The other example comes from Intel Corporation's surviving strategy.

2. Burgelman studied the processes leading Intel Corporation to transform itself from a memory company into a microcomputer company (Burgelman, 1994). Intel established as the leader in semiconductor memories in 1969. It introduced DRAM in 1970 for the first time in the world market and was very successful in the DRAM industry in the early to mid of the 1970s. DRAMS replaced the magnetic cores as the standard technology used to store instructions and data in the computer. DRAM sales accounted for $90 \%$ of Intel's sales revenue. Intel's DRAMs were the world's largest selling semiconductor product and were seen as the technological driver for Intel. The company allocated ample resources for its fast-growing DRAM business.

Important competitive products introduced in DRAMs like Texas Instruments and Mostek were the early entrants. Mostek introduced products which increased the user-friendliness in DRAMs. There was a reduction in the usefulness of Intel's Memory Systems Operations. Japanese companies also entered with the intention to dominate and led to stiff price competition and aggressive capacity. Because of the migration of the semiconductor companies in the US it was becoming increasingly difficult to profit from intellectual value added in DRAMs. With the maturity of DRAM industry consumers started demanding DRAMs in bulk with reasonable reliability and price. This shift favoured Texas Instruments and Japanese more than Intel. Intel struggled to maintain a competitive advantage. Intel's market share fell from $82.9 \%$ to $1.3 \%$ in a period from 1974 to 1984 .

Intel had developed microprocessors as an unplanned new technology as part of a contract with Japanese calculator company. By the mid-1980s Intel made a shift from the semiconductor memories to microprocessors and exited the DRAM business completely in November 1984.

The aforementioned stories are very similar; both the companies were world leaders and had the highest market shares. The situation turned around when they faced intense competition or changing market situations. The difference lies in the way the two firms responded. Intel strategically moved out of the DRAMs business; they moved out of the product in which they had patents. On the other hand, Kodak was attached to the film business and did not foresee the changing market pattern, ultimately leading to the death of the company. Intel's semi-exit prevented its permanent exit from the industry.

\subsubsection{Product Line Change and the possibility of Firm Survival}

Product line changes can be used as a conscious or an unconscious strategy by the firms. As a conscious strategy, product line change can be reflective of various other factors and not just as a survival strategy. Organizations can establish new markets and technologies by introducing new products (Burgelman, 1991). Firms can use this strategy in order to attract new customers. When a company wants to increase its customer base or expand its reach to different geographical areas, it has to add new product lines or new varieties to its existing product lines to attract the demands from different segments of the market (Brown and Eisenhardt, 1995).

A firm can also add products to its mix of existing products to utilize the excess production capacity. It can also be used as a strategy to build a reputation, by introducing high price prestigious products or low price prestigious goods to serve low-income groups. As an unconscious strategy, product line change can be reflective of the case whereby a firm in order to survive merges its operations with other firms. Even if the firm does not lose its identity, it might have to adopt the product line of the other firm.

We have to be careful in considering a product line change by a firm only as a conscious survival strategy. The conscience of the firm cannot be reflected in the data. Therefore, throughout the study, we maintain the assumption that if a firm's identity is intact and it survives after a product line change, it was undertaken as a conscious strategy for survival. We ignore the firms which do not survive after a product line change as data can only be found for the surviving firms.

\subsection{Research Objectives}

For our study, we focus on a product line change as a survival strategy what we call as a semi-exit for the Indian manufacturing firms. We try to see how the product line change differs across industries varying in durability and technology intensity. In our best knowledge, this link with product line change in Indian manufacturing firms has not been studied. We make a hypothesis that durable good firms will be required more in comparison to the non-durable goods firms to keep changing their product lines in the changing business environment to survive in the industry. Also, the industries which are more technological intensive use the route of a product line change to survive. As mentioned earlier we maintain the assumption that if a firm's identity is not changed and it changes its product line, it is using this route as a conscious strategy for survival.

\subsubsection{Research Question}

We address the following key research questions:

Central research question:

What is the pattern of semi-exits through product line change across products for India?

Sub-questions:

(i) How does this pattern work out within an industry?

(ii) How does it work out across industries varying by durability?

(iii) How does it work out across industries varying with technology? 


\section{Review of Literature}

\subsection{Theoretical Papers}

\subsubsection{Economic Distress and Firm Dynamics}

A firm is economically distressed when it has negative or low current operating profitability and little opportunity to recover (Lemmon et al., 2009). This limits its long-term probability of recovery and economic value creation. In comparison, financially distressed firms have temporary difficulties of repaying their debt. While they may be profitable at present, a high leverage may lead to distress (Platt and Platt, 2006). Recovery of economically distressed firms needs a restructuring of their operations as well as strategy whereas firms in financial distress may survive after restructuring only their balance sheet.

Agarwal and Gort (2002) analyze the determinants of the probability of firm survival other than the random shocks. There is considerable literature developed on life cycle of industry and firms and their effect on survival (Caves, 1998). Models of product life cycle are well established. Systematic changes occur as a market evolves to maturity which affects the survival probability. For instance, in the early years there are ample of technological opportunities but with maturity of the product market, these opportunities decline and moves towards product refinement and cost reduction. Then the shift starts taking place towards imitation. Competition in the market is intensified because of these changes. There are cross-industry variations in terms of intensiveness in technology. The more technologically intensive an industry, higher is the rate of obsolescence. This adversely affects the survival rate of the firms.

In the model of industry dynamics, Hopenhayn (1992) gives a cutoff level of productivity below which the firms exit the industry. With increase in the fixed cost this cutoff level increases which affects the survival decision. Age of the firm also matters in shaping the growth structure of the firms, in the learning-by-doing process given by Arrow (1971) older firms are advantaged with respect to their younger counterparts in terms of efficiency which determine their possibility of growth. In the Jovanovic (1982) model of passive learning, younger firms grow faster than their older counterparts as in the early years of firm's life they do not clearly know their level of productivity so they experiment more, so the rates of growth are greater as the updating is stronger. Active learning framework of Ericson and Pakes (1995) predicts firms will stop investing after reaching a certain level of efficiency.

Organizations adapt and reinvent themselves in the changing market and technological conditions through the channel of product creation (Schoonhoven et al., 1990). It also improves market share and firm survival (Banbury and Mitchell, 1995). Study by Katila and Ahuja (2002) through their findings in the global robotics industry show how organizations differ in the way they utilize their existing knowledge and also how they explore new knowledge, which will affect the rate at which the products are reintroduced within an organization and in a way their survival.

\subsubsection{Competition with Durable Goods}

The market structure changes with durable goods, as the consumer who has bought the good today is not likely to buy it tomorrow. Because of this feature of durable goods, a durable goods monopolist becomes his own competition. Waldman (1993) shows that if a monopolist markets his product by selling rather than leasing, then in many settings he will have an incentive to practice planned obsolescence i.e., he will introduce new products that make old units obsolete at a very high rate. For instance, automobile manufacturers introduce annual style changes into their new model cars or textbook publishers periodically bring out revised editions of their popular books. The reason is that, the firm will not internalize how its current behavior affects the value of units previously sold while deciding whether to introduce the new product. Bulow in his 1986 paper showed that a monopolist in order to sell more in the second period may build a level of durability into its output that is below the socially optimal amount.

A monopolist has a considerable power in the market. Monopoly distortion results from his pricing structure. For the market behavior in the durable goods monopoly, two conjectures have been made. These two are contradicting in nature and depends on the basic assumptions about the market (Fehr and Kuhn, 1995).

Coase Conjecture: Developed by Ronald Coase in 1972; a monopolist selling durable goods in a market where re-selling is not possible facing consumers with different valuations will have to sell at a low price if he wants to do intertemporal price discrimination. The monopolist faces a price competition with himself over several periods. If the highest valuation buyer has enough patience he can give a credible threat of waiting unless price falls. Future price expectations are embedded in the price at which consumers are willing to buy in any given period. Therefore in the limit when the period between price adjustments converges to zero, the producer of durable goods loses all his monopoly power.

Pacman Conjecture: it is in contrast with Coase conjecture and holds that monopolist selling durable goods have complete control over their market power and extract total surplus.Bagnoli et al. (1989) theorized that if consumers follow 'get-it-while-you-can' strategy i.e. if they buy a good as soon as its price dipped below a specific level, monopolist can set very high prices initially and then gradually reduce his prices eating his way down the demand curve. In this way he can extract the entire surplus.

Coasian outcome is a unique subgame perfect equilibrium if the buyers are patient enough in models where demand is continuous and with smallest unit of account. And it is Pacman strategy which is a unique subgame perfect equilibrium if the sellers are more patient in markets with finite number of buyers and a continuous price space (Fehr and Kuhn, 1995). They also show that qualitative features of the equilibrium outcome are strikingly similar for oligopolistic market structure.

Durable good monopolist faces a different problem from the producers of non-durable goods because the sale of their products creates a second hand market (Bulow, 1982). This market is not directly controlled by the monopolist. This problem can be tackled if the monopolist rents his good rather than selling it. This idea was formalized by Bulow (1982) and Stokey (1981). By renting rather than selling the problem of intertemporal credibility can be avoided. Leasing may pose hazards for the consumers if the monopolist can discriminate between them on the basis of past consumption patterns to seek higher rents which reduce current period's consumption. Oliver and Tirole (1988) proved that if the two parties sign a long term leasing contract, the market organization is same as that of selling without commitment. 
It is evident from the literature that a durable good monopolist can survive by using strategies like planned obsolescence (Waldman, 1993) renting rather than selling (Bulow, 1982); (Stokey, 1981) or signing long term contracts with the buyers (Oliver and Tirole, 1988). Firms can also earn extra revenues by controlling the market of second-hand goods (Bulow, 1982). Another important strategy can be how Organizations adapt and reinvent themselves in the changing market and technological conditions through the channel of product creation (Schoonhoven et al., 1990). Firms may change their product line when they find that growth in demand generation is declining and then may find new avenues which maybe related to the previous product or unrelated to invest into. This is an important strategy especially for the duable goods seller because of the nature of the good as in comparison to the firms producing less durable goods as they do not face an additional problem of low pace of demand regeneration.

\subsubsection{Product Line Change and Network Effects}

Farrell and Saloner (1985) theorized the effect of installed base of durable goods on the desirability of innovation. There is a possibility of excess inertia: a socially excessive reluctance by the agents to switch to a superior technology in the presence of important network externalities. All the users do not have the same opportunities at the same time, so when there is an unexpected change in technology, the new users have options not available to the old users. The old users remain somewhat committed to the previous technology, and it takes time for the network of the new technology to grow. Failure of Dvorak keyboard is an example of this. Dvorak keyboard became available when QWERTY keyboard was in use (David, 1985). Since existing users were reluctant to shift to the new technology, the new users also did not find it profitable to make the switch, even if that was more efficient.

On the contrary there is also a possibility of excess momentum: inefficient adoption of the new technology, supposing the new technology offers the adopter an advantage over the existing technology. Once he adopts, the new technology becomes even more attractive to the new and existing users. The unique Nash equilibrium then is to adopt the new technology.

The size of the existing installed base critically determines the adoption and can act as a potential barrier to entry. Strategies such as 'premature announcements' or 'predatory preannouncement' could undo the effect of installed base by creating an incentive for the new users to become a part of the existing base if they can wait. It increases the network of the new capacity once it is adopted and also the base of the existing technology reduces by the number of users who wait.

When the users are firms, their eagerness to switch will depend on the condition of its equipment currently in use, whether or not they need replacement. And it will also depend on how the rival firms are switching to the new technology. The firms may be reluctant to switch (excess inertia), too eager to switch (excess momentum) or switch efficiently. This is an empirical question and depends on the rigidities faced by firms in product introduction. Therefore, high-tech firms have an additional incentive to reinvent themselves in the related product or may even change the product basket as a survival strategy if the other firms are transforming products at a very fast pace.

\subsection{Empirical Papers}

\subsubsection{Product Line Change in the US}

A model of multi-product firm and product switching by Bernard et al. (2010) is a natural extension of the standard model of industry dynamics which is trying to capture a broad range of models which feature product selection. The model focuses on the factors peculiar to firm-product pairing i.e., interaction between the idiosyncratic shocks to the productivity of firms and the demand of the product. For instance, an idiosyncratic shock to the firm productivity might increase the profitability of all the products a firm produces or firm-specific shocks involving changes in relative demand or supply like changing fashion or technology which affects a particular product produced by firms.

They analyzed product switching in the US manufacturing firms in the period from 1987-1997 and found that one-half of the firms alter their mix of products every five years. It also induced huge changes in the firm scope as the empirical evidence showed that on an average 40 percent of the firms, added products outside their industries. There was also an evidence of a positive correlation between product adding and dropping. They showed that multi-product firms have higher measured revenue-based productivity as compared to single product firms. This difference can be understood in terms of the ability of a more productive firm to cover the fixed costs of multiple products.

Product creation and destruction are crucial for long-run growth models and for understanding fluctuations in the business cycle. There is not enough empirical analysis to study its overall implications. Broda and Weinstein (2007) studied a large sector of the U.S. economy and found evidence of net creation (creation-destruction) being strongly pro-cyclical and driven primarily by pro-cyclical creation rather than counter-cyclical destruction. They studied the impact of true product creation and destruction on consumer price index (CPI) which is effectively more pronounced than what is theorized as these are fixed-goods price indices and do not take into account the quality improvement of the new goods on consumer welfare.

\subsubsection{Product Line Change in India}

On similar lines, a paper by Goldberg et al. (2008) analyzed multi-product firms and product turnover in India during the period of market reforms. Developing country differs in the way resources are allocated in the industries which affect the efficiency of allocation as the firms operate in different regulatory environments (Tybout, 2000). Indian firms faced constraints in the form of license raj and Industrial dispute Act (1947) which heavily regulated the private sector. Reforms were introduced in 1991 which liberalized trade. Indian multi-product firms similar to the US firms were found to be larger and more productive as compared to the single product firms. They found evidence of a lack of product shedding in the Indian firms, which shows that creative destruction was not happening in the ' 90 s despite major reforms during this period. They divided the firm activity into four categories; 
add only, drop only, both add and drop and no activity. Data showed that for a five-year average, 72 percent of the firms did not change their product line. Out of the firms changing their products, 22 percent of the firms only added products. One possible explanation is the high sunk costs incurred by the firms that wanted to expand production during the time of restrictive policies like industrial licensing. Once incurred firms were reluctant to withdraw production even when the products became unprofitable. On the contrary, it might also reflect growth in the Indian economy. Because of wealth inequality, there can always be a demand for older products.

Goldberg et al. (2008) also showed that while product shedding is an important channel through which firms adjust their output in the United States, its contribution to changes in output in India is negligible. Theory suggests that lower trade costs lead firms to reduce their extensive trade margin by dropping their relatively unproductive products. The least productive domestic firms exit and all firms reduce product scope. This leads to productivity growth within and across firms and in the aggregate, but Indian firms do not show this pattern. In conclusion, product churning was found to be substantially lower among the Indian firms and had been almost driven almost entirely by product additions rather than the shedding of existing product lines.

\subsection{Contribution to the Literature}

We contribute to the existing literature by bringing to light that there is a significance of product line change for firms producing durable and technologically intensive goods and this strategy may improve their performance and act as survival strategy. The problem of firms producing durable goods and technologically intensive goods has been studied theoretically in the literature and how it changes competition in the market. This thesis will contribute to our understanding of this issue in the context of India.

\section{Research Methodology and Data}

In order to assess product line change by firms varying in the level of durability and technological intensiveness of the products we use difference-in-differences (DD) estimation method. Section 3.1 explains the general DD framework and 3.1.1 explains how we use DD estimation method in our analysis. The source used for extracting data is elaborated in section 3.2.

We use the statistical analysis to find if the data reveals a difference in the outcome of firms changing a product line versus those firms which are not. Since the data does not provide micro level information of products produced by a firm we also do case studies to show different patterns and effects of the strategy. In Appendix 1, we show an alternative result assuming a scenario in which product line change is an exogenous strategy for firms and find the difference in the means for the two sets of firms using average treatment effect on the treated by propensity score matching.

\subsection{Difference-in-Difference Estimation}

Difference-in-differences (DD) is a statistical technique that attempts to study the causal effects of programs when the program is not applied as a randomized control trial. The simplest set up is when the outcomes are observed for two groups; treatment and control, and two periods; before and after the program. The treatment group is exposed to the program in the second period whereas the control group is not exposed to it in either period. Without a random assignment, we cannot be sure whether the difference between the two groups is due to the program or some unobservable factors. To find the causal effect of the program, the average gain of the control groups, i.e., the difference between the average outcome before and after the program is subtracted from the average gain of the treatment group. This removes the bias that could arise in the treatment group as a result of a time trend as the comparison is made over time and also the bias in the second-period comparison of the two groups that could arise due to permanent differences within the groups. Quality of the evaluation depends on how well we can estimate the counterfactual (Angrist and Pischke, 2008), (Wing et al., 2018).

\subsubsection{Regression Framework for Two Groups and Two Periods}

$$
Z_{s t}=\beta_{0}+\beta_{1} P_{t}+\beta_{2} T_{s}+\delta D_{s t}+\beta_{3} X_{s t}+\varepsilon_{s t}
$$

Where $\mathrm{t}$ denotes the two periods $\left(\mathrm{t}=\right.$ pre, post) and $\mathrm{s}$ denotes the two groups (s= control, treatment). $P_{t}$ is the dummy for observations in the post period; it does not have subscript $\mathrm{s}$ as time period does not vary across groups. $T_{S}$ is the dummy for treatment group i.e. $T_{s}=1[\mathrm{~s}=$ treatment $]$, it captures the time-invariant group differences. $D_{s t}$ is the dummy for treatment group in the post period i.e. $D_{s t}=1[\mathrm{~s}=$ treatment \& $\mathrm{t}=\mathrm{post}]$. $Z_{s t}$ is the dependent variable. $X_{s t}$ denotes controls and $\varepsilon_{s t}$ is the error. Coefficient $\delta$ is of interest and can be denoted as the following (Wooldridge, 2012).

$$
\widehat{\delta}=\left[\left(\bar{z}_{\text {Treatment,post }}-\bar{z}_{\text {Treatment,pre }}\right)-\left(\bar{z}_{\text {Control,post }}-\bar{z}_{\text {Control,pre }}\right)\right]
$$

The expected value of the dependent variable given the controls is given by:

$$
E\left(Z_{s t} \mid X_{s t}\right)=\beta_{0}+\beta_{1} P_{t}+\beta_{2} T_{s}+\delta D_{s t}+\beta_{3} X_{s t}
$$

We explain the coefficients through Table 1 given below (Wooldridge, 2012) and describe the two equivalent ways of finding the DD estimate.

Table-1. Coefficients of DD estismation.

\begin{tabular}{lr|c|c|c}
\hline \multicolumn{5}{c|}{ Table-1. Coefficients of DD estismation. } \\
\hline $\begin{array}{l}T_{s}= \\
\text { (Treatment) }\end{array}$ & $\boldsymbol{P}_{\boldsymbol{t}}=\mathbf{1}$ (Post) & $\boldsymbol{P}_{\boldsymbol{t}}=\mathbf{0}$ (Pre) & Difference \\
\hline $\begin{array}{l}T_{s}= \\
(\text { Control) }\end{array}$ & $\beta_{0}+\beta_{1}+\beta_{2}+\delta$ & $\beta_{0}+\beta_{1}$ & $\beta_{2}+\delta$ \\
\hline Difference & $\beta_{0}+\beta_{2}$ & $\beta_{0}$ & $\beta_{2}$ \\
\hline Source: Wooldridge (2012). & $\beta_{1}+\delta$ & $\beta_{1}$ & $\delta$ \\
\hline
\end{tabular}

Source: Wooldridge (2012). 
The values in the cell are expected values from the regression function. The DD estimate can be computed in two ways:

1. Horizontal and then vertical: first horizontal difference is the difference across time in the treatment group i.e. $D_{1}=\beta_{2}+\delta$ and the second horizontal difference is the difference across time in the control group i.e. $D_{2}=\beta_{2}$.

DD estimate is $\mathrm{D}=D_{1}-D_{2}=\delta$.

2. Vertical and then horizontal: first vertical difference is the difference in the treatment and control group variables in the period after the program is implemented i.e. $D_{3}=\beta_{1}+\delta$ and the second vertical difference is the difference in the two groups in the period before the program was implemented i.e. $D_{4}=\beta_{1}$. The DD estimate is $\mathrm{D}=D_{3}-D_{4}=\delta$.

$D_{1}$ can be partially due to the program but can also be influenced by exogenous time trends which might not be present before the program but only after it. To control for such exogenous trends we take a control group in which the program does not take place, data is collected during the same periods and the second difference $D_{2}$ is obtained. If we can assume that what happens in the control group can be reflective of the trend in the treatment group then $D_{2}$ can be taken as an approximation of it. Difference-in-differences $\left(D_{1}-D_{2}\right)$ is computed to reflect the pure effect of the program net of exogenous trends on the outcome variable.

Similarly $D_{3}$ can be seen as a sum of the program effects and factors which are different between the two groups which have nothing to do with the program, if we can make an assumption that these factors were the same even when the program was not implemented then $D_{4}$ can be taken as an approximation of those factors to obtain the net effect of the program on the outcome variable. Difference-in-differences is computed as $\left(D_{3}-D_{4}\right)$. The two DD estimates are algebraically the same.

Regression formulation facilitates the estimation of the parameters and their standard errors. It is easy to add controls in the regression framework. The key assumption behind DD is that in the absence of the program, the average change in the outcome variable would have been the same for both the groups; this assumption is called parallel trend assumption. It is the most critical assumption for the internal validity of the model. One can use visual inspection to see whether it holds (Angrist and Pischke, 2008). The trend lines for the two groups need not coincide with each other but should be parallel over time.

\subsubsection{DD for Product Line Change}

Although, we have mentioned the set-up in terms of two groups and two time periods, the idea of DD is more general. Additional groups and periods can be added. Subscript s denotes two states which could represent for instance different demographic groups. Instead of time, we might categorize data by different cohorts or characteristics (Angrist and Pischke, 2008). In our analysis we use the DD estimation method in a slightly different way. In this analysis treatment is in terms of a conscious strategy of a firm in which it changes its product line in the period 2008-2017. A treatment is an exogenous variable whereas in our methodology the strategy of product line change is an endogenous variable, therefore we are using a DD model. It is a planned strategy of a firm which depends on various factors like the market conditions, firm's financial status and the risk taking ability of the top management (Burgelman, 1991). We analyze this strategy across two industries differing in the level of durability and technology. The two industries chosen are electronics and food.

We define a change in product line change as it is defined in Goldberg et al. (2008) paper. They have divided firm activity into four mutually exclusive groups: add products, drop products, both add drop and no activity. A product is added if it is produced in period t but not in period $t-1$. A product is dropped if it was produced in period t-1 but not in period t. So a firm is said to change the product line if it is involved in any of the first three activities whereas no activity means that firm is keeping the product basket same. Therefore, in our analysis we say that a firm has changed its product line if it either adds product, drops product or both and add and drop products over a period of 10 years i.e., from 2008-2017, whereas it is said to not change product line if there is no change in the product basket for the same period. Product line changes are observed for the main products. The main product of a firm is that product from which the company gets more than half of its revenue. But we observe the activity for products from which the company gets at least ten percent of its revenue.

More patterns of product line change are possible, for instance product reintroduction. A firm may discontinue a product, introduce other products and might then later resort to the same product discontinuing the new products if it finds it is not profitable. We have mostly observed the first three patterns in the data. Decadal time is assumed to be a sufficiently long time period for a firm to adjust its product line. Firms which have not adjusted their product line within 2008-2017 may or may not have chosen this strategy outside the period in consideration. Both the sets of firms maybe additionally using other strategies for survival during this time but we would like to study product line changes in exclusion.

We define the two groups as the two industries; electronic and food. Definition of product and industry is based on CMIE's internal product classification. An industry is defined at a 2-digit NIC code and product at 4 or 5 digit classifications. An electronic industry firm is expected to produce goods which are more durable than the goods produced by food industry firm. For instance, television, mobile phones, cables, printers, control valves, DVD players etc. are more durable than goods like tea, coffee, butter, milk, chocolate confectionary etc. produced by the latter. Technologically also the goods differ. According to Pavitt (1984) electronic industry firms are science-based, high-tech firms which rely on R\&D, whereas, food industry firms are supplier dominated which includes firms from traditional manufacturing. We therefore compare the firms changing and not changing product line within 20082017 and the comparison is done across two industries differing in the two dimensions mentioned using electronic and food industry.

To be consistent with the DD terminology, in this analysis treatment and control groups are electronic and food industry firms respectively. Instead of the two time periods we might categorize data by different cohorts or characteristics (Angrist and Pischke, 2008) therefore we define the cohort 'pre' as the outcome variable observed for those firms which have not taken up the strategy within 2008-2017. We call it pre because they may or may not 
have used this strategy before 2008, but not in 2008-2017, and 'post' is the outcome variables for firms which have changed product line after 2008.

\subsubsection{Definition of Variables \\ 3.1.3.1. Dependent Variable}

The dependent variable is the log of the value of gross sales for a firm averaged for 10 years from 2008-2017. A sale is as an act of transferring a product or service in return for cash or other non-cash consideration. Value of sales includes regular income generated by a firm from sales of identifiable goods and non-financial services. It includes the sale of scrap, raw materials, and stores, income from job-work done, repairs and maintenance, construction and utilities.

Sales and not the number of products produced by a firm are considered for two reasons. First, it allows comparison under a common unit for multiproduct firms. Second, price is also an important consideration for a firm to discontinue or introduce a product. Value of sales captures both the quantity effects and the value effects.

\subsubsection{Measurement of Dependent Variable}

For each firm, we find the average sales value for the 10 years, i.e., for years 2008-2017. We also check if the mean is an appropriate measure of central tendency by finding the standard deviation for each firm for the sales values over this period. We then calculate the coefficient of variation for each firm which is a ratio of standard deviation and means. We find that the coefficient of standard deviation is less than 1 for each firm, i.e., mean is greater than the standard deviation which implies that mean contains much information of the data. Since all the values are uniformly bounded below 1, we can therefore, do the regression at the means. Sales values are large numbers; we use the log transformation of the sales value to remove the problem of heteroscedasticity by reducing the scale effect of the number.

The analysis can also be done using panel data, but due to time constraint we are restricting to cross-section analysis. We represent the time series of a variable for a firm by an average of the values for the years 2008-2017 assuming it to be a reasonable representative because of the reasons mentioned above.

\subsubsection{Independent Variables and Controls}

We include the dummy for electronics and food industry [Industry $]_{s}$ that takes value one if firm belongs to electronic industry and zero if it belongs to food industry. This dummy would capture the industry specific features determining the performance. Dummy for post and pre firms is [Post $t_{t}$ that takes value one if a firm changes product line within 2008-2017 and zero if it does not. Our variable of interest is the interaction dummy [Post ${ }_{t} *$ Industry $_{s}$ ] which takes value one if a firm belongs to electronic industry and changes product line and zero otherwise. It would give an estimate of the difference between the average sales value of electronic industry firms changing product line and food industry firms not changing product line.

\subsubsection{Controls}

We control for firm characteristics such as age [Age] and size of endowments [Average Total Assets] which explain variations in the probability of survival (Agarwal and Gort, 2002). Age of the firm relates to knowledge that a fir acquires that leads to cost reductions, and product improvements. And the endowments affect how a firm is inherently suited for profitable production. Additionally, we control for costs of sales and manufacturing [Average Cost of Manufac. and Sales]. As the costs differ in the two industries, it will affect the decision of product line change for the firms in different industries.

\subsubsection{Variable Measurement}

Age of the firm is measured as the current year minus the year of incorporation. Average size of endowment is measured as the book value of total assets of a firm averaged for 2008-2017. Total assets are a common proxy for size (Balcaen et al., 2011). Cost of sales is the cost involved in manufacturing and selling a product during a year. It is different from the cost of goods sold. Cost of goods includes only the direct costs for production of goods and ignores the cost of selling and distribution. Average cost of sales is used which is the average of cost of sales for year 2008-2017.

We define the DD model as:

$$
y_{s t}=\alpha+\gamma \text { Post }_{t}+\lambda \text { Industry }_{s}+\delta\left(\text { Post }_{t} * \text { Industry }_{s}\right)+\beta X_{s t}+\varepsilon_{s t}
$$

where, Post $_{t}$ is a dummy for firms changing product line in the period 2008-2017 and Industry Is $_{s}$ the dummy for electronic industry firms. Post $t_{t}$ Industry $_{s}$ captures the interaction effect. The outcome variable is $y_{s t}$ i.e. the natural $\log$ of average sales value for firms, averaged for years 2008-2017. $\varepsilon_{s t}$ is the error.

$\hat{\delta}=\left[\left(\bar{y}_{\text {Electronics,Post }}-\bar{y}_{\text {Electronics,Pre }}\right)-\left(\bar{y}_{\text {Food,Post }}-\bar{y}_{\text {Food,Pre }}\right)\right]$

The first and the second parentheses show the difference between firms changing product line and not changing product line. The difference is across the two industries varying in durability and technology of the products produced. Hence this is a difference-in-differences analysis. We try to capture the differential impact of product line changes controlling for technology and durability of products on the average sales value.

\subsection{Data}

We compile the data from Prowess ${ }_{\mathrm{dx}}$ database, collected by Centre for Monitoring the Indian Economy (CMIE). It is a database of the financial performance of companies delivering data for over 40,000 Indian companies including listed companies, unlisted public companies and private companies of all sizes and ownership groups. It is the only database in our knowledge that records detailed annual information of the product mix of a firm. By the 1956 Companies Act, firms are mandated to disclose the information about capacities, sales and production at the 
product level. Prowess database compiles this data and hence allows us to track whether the firm has changed its product line over the period 2008-2017.

We categorize a firm as electronic and food industry by matching the NIC product code at digit classification 4 and 5 given by prowess for the products of a firm with the NIC 2008 industry code. In case of a multi-industry firm, the categorization is done according to the code of the main product of the firm or the product from which the firm earns the highest revenue.

For each firm we collect data on sales value which includes industrial sales and income from non-financial services. Industrial sales includes the sale of goods and income from activities associated with sales like sale of scrap, raw materials and stores, income from job-work done, and income from repairs \& maintenance, construction and utilities. It includes fiscal benefits received by a firm. The other variables are cost of sales and manufacturing, age of firm, total assets of firms, profit ratios like PBIDTA/total income, PAT/Net worth. All these values are collected for years 2008-2017.

\section{Results and Discussions}

For descriptive statistics, we make the calculations using the compiled dataset and tabulate the values separately for the firms belonging to electronic and food industry, similarly for the set of firms which adopt a product line change within 2008-2017 and the set of firms that do not. We also tabulate the mean of different industry-specific features for the two groups and test the difference in means using Wilcoxon Rank sum test. Descriptive statistics and the results from means test are given in Appendix 1. In section 4.1 we give the estimates of DD analysis. Since the data does not capture micro-level changes that take place within a firm, we take some case studies to discuss the effects of product line change in section 4.2. In Appendix 2, we show an alternative result by assuming product line change is an exogenous strategy of the firm to show how sales value would react to the strategy across the two sets of firms. This is a big assumption and is difficult to fulfill therefore we use this result only to indicate what could happen had the assumption held true. We find the average treatment effect on the treated by using propensity score matching for the two industries separately and report the results in appendix 2 .

\subsection{Difference-in-Differences Estimation}

Parallel trend assumption is the most crucial of the assumptions mentioned for the internal validity of DD model. Figure 4 Appendix 3 shows a plot of average sales value against years for the two industries for the firms not showing change in product line. Figure 5 Appendix 3 shows the same plot for the log of average sales values against years. From the figures we can infer that there is an upwards trend for both electronic and food industry firms. The electronic industry besides having an upwards trend is also affected by business cycle fluctuations more than food industry. The trend lines for the two industries for firms which have not undergone a product line change are not exactly parallel but still show similar patterns. While we do not find exact evidence for the parallel trend assumption, we do not find evidence to reject it either. We work with it in our analysis that follows, and in our future exploration with panel data, we shall formally test for it.

\subsubsection{DD Estimates}

DD equation is given by:

$$
y_{s t}=\alpha+\gamma \text { Post }_{t}+\lambda \text { Industry }_{s}+\delta\left(\text { Post }_{t} * \text { Industry }_{s}\right)+\beta X_{s t}+\varepsilon_{s t}
$$

Table-2. Estimates of DD model.

\begin{tabular}{l|c|c|c}
\hline Variables & Model 1 & Model 2 & Model 3 \\
\hline \multicolumn{1}{c|}{ Post $_{\mathrm{t}}$} & -0.068 & -0.124 & -0.748 \\
\hline \multicolumn{1}{c|}{ Industry $_{\mathrm{s}}$} & $-0.875^{* *}$ & $-1.344^{* * *}$ & $-1.021^{* *}$ \\
\hline Post $_{\mathrm{t}} *$ Industry $_{\mathrm{s}}$ & 0.866 & $1.112^{* *}$ & $0.968^{* *}$ \\
\hline Age & & $-0.251^{* * *}$ & $-0.234^{* * *}$ \\
\hline Average total assets & & $-0.001^{* * *}$ & $0.0006^{* * *}$ \\
\hline Average cost of & & & $0.0012^{* * *}$ \\
manufac. and sales & & & $(0.000039)$ \\
\hline Constant & $6.905^{* * *}$ & $7.401^{* * *}$ & $7.061^{* * *}$ \\
\hline \multirow{2}{*}{ No.of obs $=229$} & No.of obs $=229$ & No.of obs $=229$ \\
& $\mathrm{~F}(3,225)=2.930$ & $\mathrm{~F}(5,223)=17.06$ & $\mathrm{~F}(3,225)=14.74$ \\
& Prob $>\mathrm{F}=0.034$ & Prob $>\mathrm{F}=0.000$ & $\begin{array}{c}\text { Prob }>\mathrm{F}=0.000 \\
\mathrm{R}^{2}\end{array}$ \\
& $\mathrm{R}=0.037$ & $\mathrm{R} 2=0.431$ \\
\hline
\end{tabular}

\subsubsection{Inference}

Table 2 shows the estimates of DD model. In model 2 after controlling for age and size of the firms the parameter of interest i.e. the coefficient of the interaction term Post $_{t} *$ Industry $_{\mathrm{s}}$, is positive and is statistically significant at 5 percent level of significance. Since the dependent variable is in $\log$ terms the coefficient of 1.112 means that controlling for age and size of firms on an average, the average sales value for electronic industry firms which are changing product line is approximately 111 percent higher than the food industry firms which do not change product line. In model 3, when there is an additional control for average cost of manufacturing and sales the coefficient of 0.968 means that controlling for costs, size and age, on an average the average sales value for electronic industry firms which are changing product line is 96.8 percent higher than food industry firms which do not change product line. The coefficient is significant at 5 percent level of significance. In the first model, the coefficient is significant but it is not statistically significant.

Other coefficients are also of interest. For instance the coefficient for Industry Is -1.344 which means after controlling for age and size of firms, on an average the average sales value for electronic industry firms not 
changing product line is approximately 134 percent lower than food industry firms not changing a product line. The coefficient is significant at 1 percent level of significance. The sign is as expected; because of the nature of products in electronic industry, the firms not changing product line are performing badly than firms not changing product line in food industry firms. The coefficient for the other models can be interpreted in the same way.

The sign of Post $\mathrm{t}_{\mathrm{t}}$ is also according to the expectation though not significant. Negative sign implies that the firm changing product lines in the food industry are performing lower than the firms not changing product line; because of the nature of the product, consumers demand the good more often, therefore the firms need not reinvent themselves in order to survive.

From the empirical evidence we can infer that product line change is playing an important role for firms as a strategy. Even though the data masks a lot of micro level changes happening within a firm still we can find evidence when we measure the strategy of changing product lines through the impact on average sales of a positive performance of firms involved in changing product line and the change is more pronounced in electronic industry firms. Still not many firms are using this as a strategy for survival; the probable reasons of this are discussed in section 4.2 .

\subsection{Case Studies}

Through the cases, we want to bring in light the various patterns of product line changes showing up in the firms and how the sales performance of the firms reacted to such changes. We say that a firm has changed the product line if it adds product, drops product or both add and drop products in the period from 2008 to 2017 from which it accrues at least 10 percent of its sales value. We first try to understand why this strategy might not be popular amongst firms and also show under what conditions keeping the product basket same be a feasible strategy. We also find evidence of manufacturing firms turning into service providers which is another kind of product line change where firms enter into a different domain of business to survive. At the end, we indicate the presence of complementarities amongst different goods of a firm and the potential repercussions to reputation by changing the products which is an additional cost of product line change.

The first case is of Wrigley India Pvt. Ltd., a food industry firm that had produced bubble gums, chewing gums, lollipops, and toffees from 2005-2011. From 2012-2015 continuing with the same product line it also produced pharmaceutical products and prepared food products accounting for almost 13 percent of its sales revenue in 2012 and 19 percent of the sales revenue in 2014. In 2016 it discontinued the added products and continued the previous line. Data on cost of sales and manufacturing reveals that the cost increased by 21 percent from 2011 to 2012 when it introduced the new products and fell by almost 4 percent in 2016 when the new products were discontinued. The cost had been relatively stable and high in the period from 2012-2015. The cost of raw materials, advertisements and marketing as percent of sales increased by about 35 percent, 3.5 percent and 7.5 percent respectively in 2013-14. These measures showed a slight decline in the period 2016-17 when the added products were discontinued. These findings hint at the additional cost burdens of product line change for a firm. Though, the added products add to the revenues, the firm also has to incur huge cost to produce and sell the product.

A similar pattern has also been observed with Nippon Audiotronix Pvt. Ltd which is an electronics industry firm. Data shows that the firm had produced the same basket of goods from 2000-2011. After 2012 it had added various products in different years. The cost of sales and manufacturing rose by 25 percent in that year and remained high after that. The cost of raw materials, advertisements and marketing as percent of sales increased by about 6 percent, 1 percent and 2 percent in 2011-2012. Data from other firms also reveals a similar pattern.

Product line change; one of the survival strategies of firms is an expensive strategy. Introducing new products and laying product line requires capital and expertise which the firm has to acquire and additional cost in terms of raw materials, advertisement and marketing. These cases show the costs when a firm adds a product, but cost can also be associated with dropping a product line. Goldberg et al. (2008) show that Indian firms are not dropping products whereas it is an important strategy for the US firms. The change in product lines is almost driven by product addition than dropping. The plaussible reason for this could be that the management is reluctant to drop a product once the sunk cost has been paid even if the product is not profitable. Therefore, there are costs associated with both product addition and dropping because of which firms do not use this strategy very often.

The following two examples are of two electronic industry firms which have not changed the product line in period 2008-2017. For the first firm, the profit measures have reduced significantly and have become negative whereas for the second firm it has never sharply reduced and remained positive throughout the period. From these examples, we want to bring in light the fact that the market situation under which a firm operates matters for getting benefits from product lines. If a firm has control over the supply in the market, it need not alter its products and can survive and thrive even without product line change.

The first example is of Samtel Color Ltd., it had produced color TV picture tubes from 1980-1999, from 20002007 along with the TV tubes it produced black and white and colored electron guns, it discontinued black and white guns by 2008 and produced colored guns and TV tubes in the period 2008-2017. Even though the firm had introduced changes outside the period 2008-2017 but since it has kept the product line same in this period we keep it under category-2, i.e., firm not changing product line.

Form Figure 1 we can see that the profit measures have considerably reduced in the period $2008-2017$. Interestingly, the values were positive before 2008, when the firm has shown changes in the product basket. 
Samtel Color Ltd.

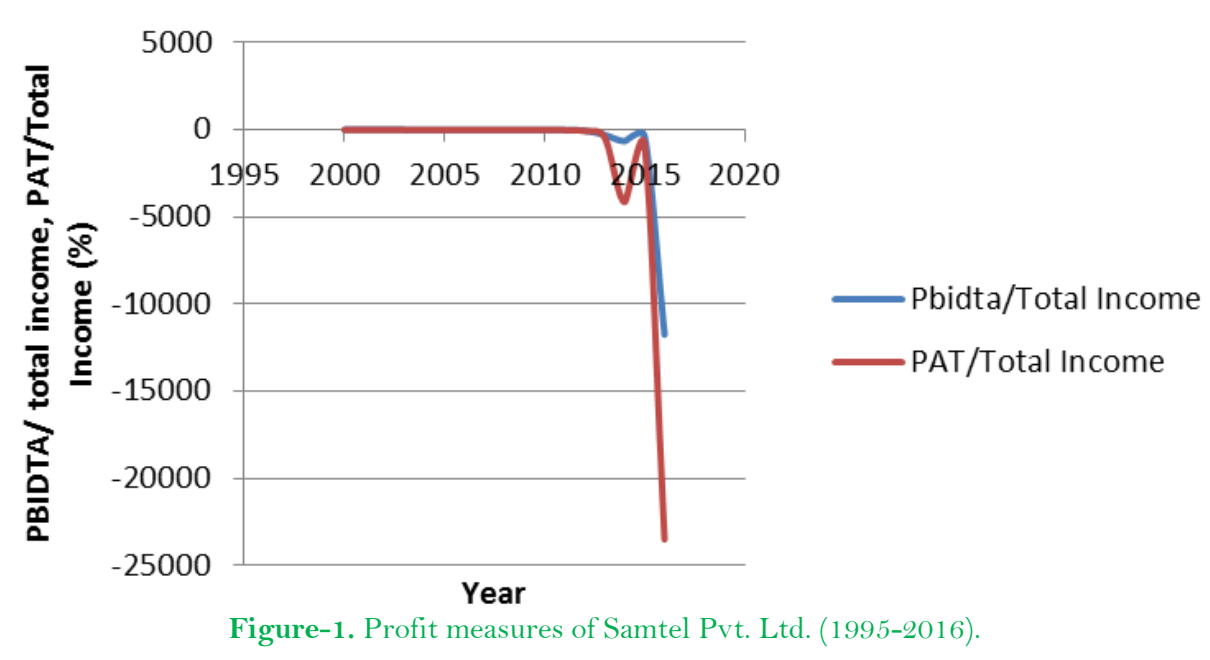

Contrary to the previous example, Bharat Dynamics Ltd. also a firm in electronic industry is a government of India enterprise and has produced first generation anti-tank missile and missile system; defense communication equipment since 1989 and has never undertaken a product line change. PBIDTA/Total income and PAT/Total Income shows a very different trend from Samtel Color Ltd.

From Figure 2 we find that profit measures have both declined and rose within 1995-2016 but have not shown significantly negative values as in the case of the previous example despite keeping product line same throughout. Hence, the position of a firm in the industry and its control over supply really matters. The first example in which a private firm is competing with other firms is showing negative profits by keeping product line same whereas, in the second example, where the firm has a semi-monopoly, product line change is not required. This indicates that product line change may help firms to survive in cases it is facing competition in the market but is not an important strategy for firms which have control over the supply. Also we should note that we cannot generalize the findings from these examples for the industry as a whole. These are particular examples to motivate certain points which one must consider for product line changes.

Bharat dynmics Ltd.

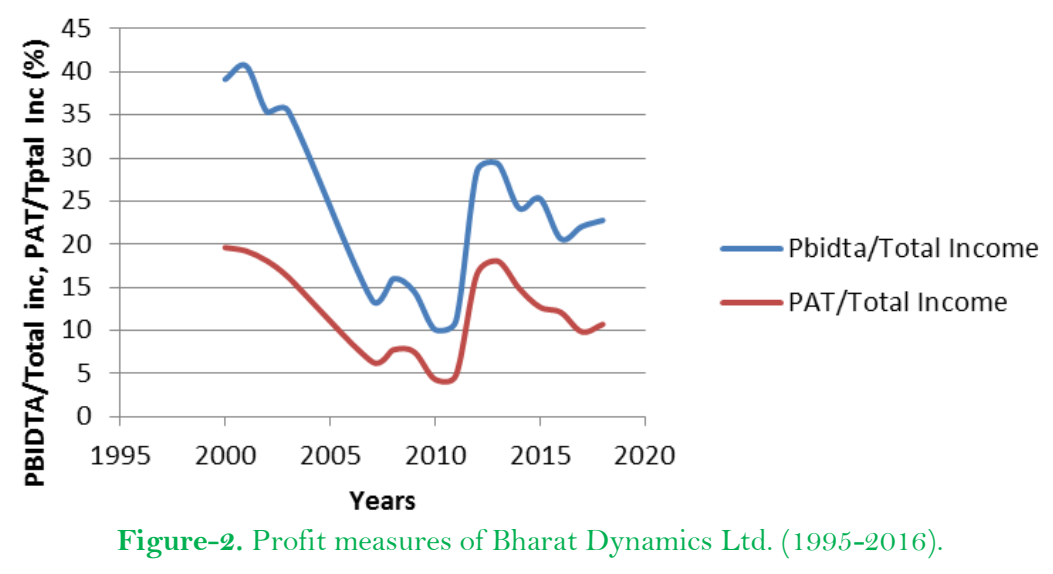

There must be firms which change their product lines and still fail as they are not able to either sell the product or have no expertise in the new product. Since the dataset contains only those firms which still exist, i.e., they are still surviving; we cannot capture those firms which have exited the market because of product line change. Hence our analysis has a survival bias which cannot be removed as the data set does not have information on firms which do not exist now. Whether firms barely survive through a product line change or survive and thrive depends on the firm and industry-specific conditions. Product line change being an expensive strategy poses an additional burden on a firm's expenses in the form of advertisement, research and development, laying new product line, etc.

Firms also adopt various other strategies which are not given much attention in the literature. For instance, Esha Media Research Ltd. an electronic industry manufacturing firm produced ultra sound scanners from 19962010. Since the sales revenue from the product continuously fell, the firm moved out of the given product line to market research \& public opinion polling and earned revenue only from these operations. Figure 3 shows the sales revenue of the firm from 1996-2014, the sales value continuously fell from 1996-2010 and increased from 2011 when the firm moved into market research services. This is also an example of product line change where a firm moves from manufacturing to services to survive. Other examples can also be found, for instance, Satva Jewelers and design Ltd. moved out of manufacturing into the fund based financial services and renting services, but the sales figure had been low throughout. 
Esha media research Ltd.

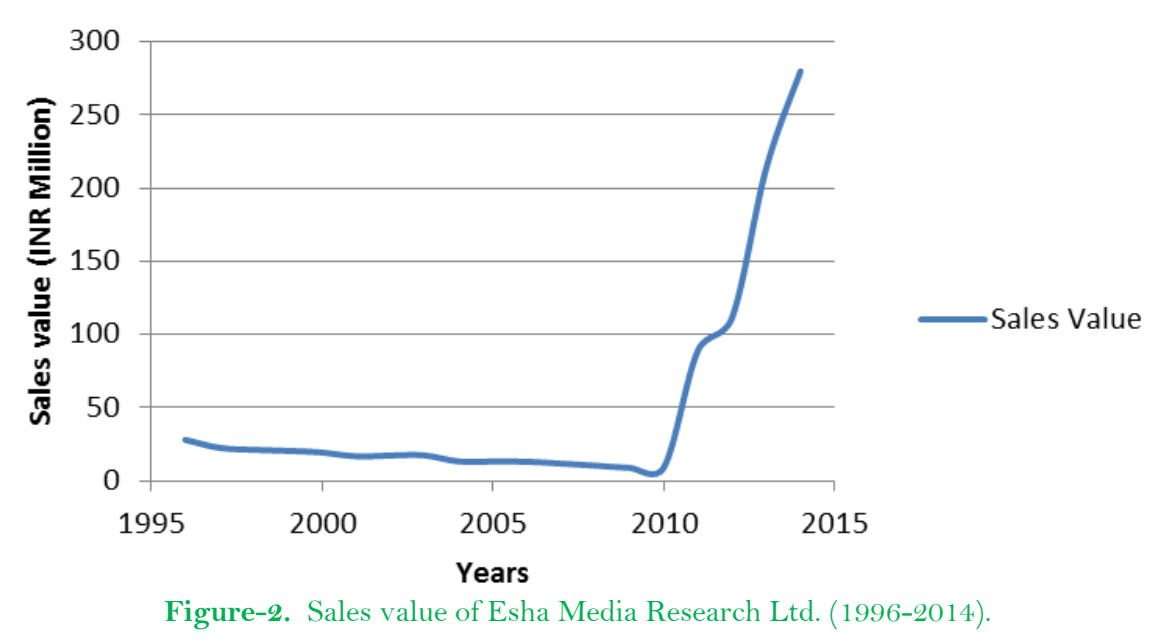

From these cases, we can see that product line change is not an ultimate strategy of survival but is important as well as an expensive strategy. Firms may or may not do well by keeping product line the same which depends on the market competition and the nature of products a firm produces. There are also other kinds of product line changes where the firm gives up manufacturing and moves into services.

There exists complementarity in the products a firm produces. For instance, the Food Safety and Standards Authority of India banned Maggi in June 2015, a flagship product of Nestle India, due to the presence of lead above the permissible limit. Their market share reduced from 80 percent to 0 percent within a month. The ban on the product also harmed the sales of the company's other products like infant milk food as the customers may have lost confidence in the company. The growth in sales of infant baby products was a little higher than 13 percent in 201314 whereas, it was only 0.9 percent post ban in 2015-16. The company did not give up the product but tried to bring it back to maintain its reputation in the market. After the Maggi noodles were back in the market, the growth in sales of infant milk food also improved to 2.3 percent in 2016-17. Hence adding and dropping products is not only expensive in terms of an additional financial requirement but also the complementarities associated with different products of a company. When a firm drops a product, customers may not find the firm to be reliable and the demand might fall. These cases point out towards the costs associated with product line changes potentially because of which there is not much evidence of this strategy found in the Indian firms.

\section{Conclusion}

In this work we presented that product line change through which a firm adjusts its basket of goods to eliminate products which are not profitable or adding products which have the possibility of earning high profits is a crucial strategy for any firm. It allocates resources efficiently which is of paramount importance for the economy as a whole. We studied this strategy for the manufacturing industry of India focusing on electronic and food industry firms as they have some specific characteristics. The former produces goods which are durable and technologically intensive and the latter produces goods which are less durable and technologically less intensive.

Linking the literature on product line changes and competition under durable and technologically intensive goods, we understood that the strategy would be beneficial more for firms producing such goods. This is precisely what we have found from the empirical analysis. Controlling for age, the average size of firms and the average cost of sales and manufacturing, the average value of sales for electronic industry firms which are changing product line is approximately 96.8 percent higher than the food industry firms which do not change product line. Through the difference-in-differences technique, we have tried to capture the two differences; the first difference is related to the difference in firms changing the product line and not changing the product line and second for firms producing durable and technologically intensive goods and those which are not.

We also tried to find an alternative result shown in Appendix 2, which depends in the assumption of product line change being an exogenous strategy of the firm. The result is in line with what we hypothesis from the literature. For firms with similar average total assets, the average cost of sales and manufacturing, average $\mathrm{PBIDTA} /$ total income and average PAT/net worth which is also the return on equity, the electronic industry firms which are changing product line are earning 82.6 percent more on an average than the firms which are not. For the food industry firms, on the other hand, these firms do worse though the result does not come out to be statistically significant. The result shows that this strategy is more useful for electronic industry firms. Although the reliability of the result is questionable since the assumption on which it depends is difficult to fulfill.

We have also seen that this strategy is not very popular amongst firms, the reason for which is that changing a product line is an expensive affair. Laying a product line requires enormous costs; not only monetary but the cost in terms of forming links with other firms, creating demand, gaining the expertise in product formation which includes training staff and managers. The cost may also include repercussions on reputation, where customers may lose faith in a company which frequently changes its products and brands. Therefore, the sunk costs of new product introduction and dropping are high. Hence it is not surprising that firms that did pay these high sunk costs are reluctant to withdraw products, even if the products turned out to be less profitable. There might also be a situation where a firm wants to change its product basket but is not able to undertake the change due to insufficient capital and lack of credit.

Also from the data, we have seen that changing the product basket is not the only strategy. Manufacturing firms may even turn into service providers or invest in other firms which are profitable to survive. Survival strategies are specific to each firm which depends on the market situation. Once we understand the bottlenecks, we can improve upon it so that firms not just survive, but survive and thrive. It is not only beneficial for a particular firm but is profitable for the economy as a whole. 


\subsection{Future Work}

Since many firms have changed their product lines just before the year 2008 and have not shown changes within 2008-2017, it is critical to shift the period window, let's say from 2005-2015 and analyze the results for a better understanding of the applicability of the strategy. Also, the analysis can be done using a panel difference-indifferences model. Due to limited time, we will do this analysis in our future work to understand more patterns of a product line change and other survival strategies.

\section{References}

Agarwal, R. and M. Gort, 2002. Firm and product life cycles and firm survival. American Economic Review, 92(2): 184-190.Available at: https://doi.org/10.1257/000282802320189221.

Angrist, J.D. and J.S. Pischke, 2008. Mostly harmless econometrics: An empiricist's companion. Princeton, New Jersey: Princeton University Press.

Anthony, S.D., 2016. Kodak's downfall wasn't about technology. Havard Business Review, 15.

Arrow, K.J., 1971. The economic implications of learning by doing. In Readings in the Theory of Growth. London: Palgrave Macmillan. pp: $131-149$.

Bagnoli, M., S.W. Salant and J.E. Swierzbinski, 1989. Durable-goods monopoly with discrete demand. Journal of Political Economy, 97(6): 1459-1478.

Balcaen, S., S. Manigart and H. Ooghe, 2011. From distress to exit: Determinants of the time to exit. Journal of Evolutionary Economics, 21(3): 407-446.Available at: https://doi.org/10.1007/s00191-010-0192-2.

Banbury, C.M. and W. Mitchell, 1995. The effect of introducing important incremental innovations on market share and business survival. Strategic Management Journal, 16(S1): 161-182.Available at: https://doi.org/10.1002/smj.4250160922.

Bedi, H.S., 2010. Merger \& acquisition in India: An analytical study. National Conference on Business Innovation by Apeejay Institute of Management. Jalandhar.

Bernard, A.B., S.J. Redding and P.K. Schott, 2010. Multiple-product firms and product switching. American Economic Review, 100(1): 7097.Available at: https://doi.org/10.1257/aer.100.1.70.

Bhatia, J., 2016. Reliance jio: Predatory pricing or predatory behaviour? Economic and Political Weekly, $51(39)$.

Broda, C. and D.E. Weinstein, 2007. Product creation and destruction: Evidence and price implications. American Economic Review, 100(3): 691-723.

Brown, S.L. and K.M. Eisenhardt, 1995. Product development: Past research, present findings, and future directions. Academy of Management Review, 20(2): 343-378.Available at: https://doi.org/10.5465/amr.1995.9507312922.

Bulow, J., 1986. An economic theory of planned obsolescence. The Quarterly Journal of Economics, 101(4): 729-749.Available at: https://doi.org/10.2307/1884176.

Bulow, J.I., 1982. Durable-goods monopolists. Journal of Political Economy, 90(2): 314-332.Available at: https://doi.org/10.1086/261058.

Burgelman, R., 1991. Intraorganizational ecology of strategy making and organizational adaptation: Theory and field research. Organization Science, 2(3): 239-262.Available at: https://doi.org/10.1287/orsc.2.3.239.

Burgelman, R.A., 1994. Fading memories: A process theory of strategic business exit in dynamic environments. Administrative Science Quarterly, 39(1): 24-56.Available at: https://doi.org/10.2307/2393493.

Caliendo, M. and S. Kopeinig, 2005. Some practical guidance forthe implementation of propensity score matching. DIW Discussion Papers,DeutschesInstitut für Wirtschaftsforschung (DIW), Berlin. No. 485. Available from http://hdl.handle.net/10419/18336.

Caves, R.E., 1998. Industrial organization and new findings on the turnover and mobility of firms. Journal of Economic Literature, 36(4): $1947-1982$.

David, P.A., 1985. Clio and the economics of QWERTY. The American Economic Review, 75(2): 332-337.

Ericson, R. and A. Pakes, 1995. Markov-perfect industry dynamics: A framework for empirical work. The Review of Economic Studies, 62(1): 53-82.Available at: https://doi.org/10.2307/2297841.

Farrell, J. and G. Saloner, 1985. Standardization, compatibility and innovation. The RAND Journal of Economics, 16(1): 70-83.

Fehr, N.-H. and K.-U. Kuhn, 1995. Coase versus pacman: Who eats whom in the durable-goods monopoly? Journal of Political Economy, 103(4): 785-812.Available at: https://doi.org/10.1086/262003.

Goldberg, P.K., A.K. Khandelwal, N. Pavcnik and P. Topalova, 2008. Multiproduct firms and product turnover in the developing world: Evidence from India. The Review of Economics and Statistics, 92(4): 1042-1049.

Hopenhayn, H.A., 1992. Entry, exit, and firm dynamics in long run equilibrium. Econometrica: Journal of the Econometric Society, 60(5): 1127-1 150.Available at: https://doi.org/10.2307/2951541.

Jovanovic, B., 1982. Selection and the evolution of industry. Econometrica: Journal of the Econometric Society, 50(3): 649-670.Available at: https://doi.org/10.2307/1912606.

Kar, S. and M. Dutta, 2018. Outsourcing and productivity during economic crisis: Evidence from Indian manufacturing firms. Arthaniti: Journal of Economic Theory and Practice, 17(2): 168-182.Available at: https://doi.org/10.1177/0976747918792638.

Katila, R. and G. Ahuja, 2002. Something old, something new: A longitudinal study of search behavior and new product introduction. Academy of Management Journal, 45(6): 1183-1194.Available at: https://doi.org/10.2307/3069433.

Leggat, R., 1995. A history of photography from its beginnings till the 1920s. Available from http://www.rleggat.com/ photohistory/.

Lemmon, M.L., Y.-Y. Ma and E. Tashjian, 2009. Survival of the fittest? Financial and economic distress and restructuring outcomes chapter 11. Third Singapore Conference on Finance. Singapore. Available from https://ssrn.com/abstract=1325562.

Munir, K.A. and N. Phillips, 2005. The birth of the'Kodak Moment': Institutional entrepreneurship and the adoption of new technologies. Organization Studies, 26(11): 1665-1687.Available at: https://doi.org/10.1177/0170840605056395.

Oliver, D., Hart and J. Tirole, 1988. Contract renegotiation and Coasian dynamics. The Review of Economic Studies, 55(4): 509540.Available at: https://doi.org/10.2307/2297403.

Pavitt, K., 1984. Sectoral patterns of technical change: Towards a taxonomy and a theory. Research Policy, 13(6): 343-373.Available at: https://doi.org/10.1016/0048-7333(84)90018-0.

Platt, H.D. and M.B. Platt, 2006. Comparing financial distress and bankruptcy. Review of Applied Economics, 2(2): $141-157$.

Rosenbaum, P.R. and D.B. Rubin, 1983. The central role of the propensity score in observational studies for causal effects. Biometrika, $70(1)$ : 41-55.Available at: https://doi.org/10.2307/2335942.

Schoonhoven, C.B., K.M. Eisenhardt and K. Lyman, 1990. Speeding products to market: Waiting time to first product introduction in new firms. Administrative Science Quarterly, 35(1): 177-207.Available at: https://doi.org/10.2307/2393555.

Stokey, N.L., 1981. Rational expectations and durable goods pricing. The Bell Journal of Economics, 12(1): 112-128.Available at: https://doi.org/10.2307/3003511.

Tybout, J.R., 2000. Manufacturing firms in developing countries: How well do they do, and why? Journal of Economic literature, 38(1): 1144.Available at: https://doi.org/10.1257/jel.38.1.11.

Waldman, M., 1993. A new perspective on planned obsolescence. The Quarterly Journal of Economics, 108(1): 273-283.Available at: https://doi.org/10.2307/2118504.

Wing, C., K. Simon and R.A. Bello-Gomez, 2018. Designing difference in difference studies: Best practices for public health policy research. Annual Review of Public Health, 39(1): 453-469

Wooldridge, J.M., 2012. Introductory econometrics: A modern approcach. Michigan, United States: MIT Press. 
Appendix 1

1. Descriptive Statistics

We call the firms showing a change in their product line within 2008-2017 as Category-1 firms and the other set of firms which do not show a change in their product line within 2008-2017 as Category-2 firms. Table 3 indicates the number of Category-1 and Category- 2 firms for the two industries as in our sample.

\begin{tabular}{c|c|c|c}
\multicolumn{2}{c}{ Table-3. Number of category-1 and Category-2 firms industry wise. } \\
\hline Variables & $\begin{array}{c}\text { Electronic } \\
\text { Ind. }\end{array}$ & Food Ind. & Total \\
\hline Category-1 & 38 & 37 & 75 \\
\hline Category-2 & 78 & 76 & 154 \\
\hline Total & 116 & 113 & 229 \\
\hline
\end{tabular}

We find that the proportion of firms changing product line in both the industries is almost the same (around 32 percent). The electronic industry firms are not using the strategy more often than the food industry firms which is contrary to our understanding from the literature. The plausible reason of this could be the rigidities in product reintroduction or lack of capital or risk appetite of the firms in the industry. We discuss these further using case studies in section 4.4.

Given below are the various industry-specific features and cost characterizations for electronic industry, food industry, category-1 and category-2 firms.

\subsection{HHI Index and CR-4}

Herfindahl-Hirschman Index (HHI) and Concentration Ratio (CR) are measures of market concentration. HHI is calculated by summing the squares of market shares of firms within an industry. It ranges from 0-10,000. CR-4 is calculated by summing the percentage of market share of top 4 firms in the industry. Table 4 shows the market share of each firm calculated by dividing average sales value for period 2008-2017 of a firm by total average sales value for all firms.

Table-4. HHI Index and CR-4.

\begin{tabular}{c|c|c|c|c}
\hline Variables & Electronic Ind. & Food Ind. & Category-1 & Category-2 \\
\hline HHI Index & 782.825 & 385.576 & 423.885 & 486.487 \\
\hline CR-4 $(\%)$ & 38.91 & 31.65 & 30.31 & 36.46 \\
\hline
\end{tabular}

The US department of Justice considers a market with HHI from 0-1500 a competitive market, HHI of 15002500 as moderately concentrated and HHI of more than 2500 as highly concentrated. CR between 0-50 percent indicates low concentration market. Through both the measures both electronics and food industry are nearly perfectly competitive. Same holds for category-1 and category-2 firms.

\subsection{Values in the Descriptive Statistics}

For all the descriptive statistics given below, we provide the values of the maximum and minimum of the given variables, mean, and the average standard deviation. We calculate the mean by first calculating the average for each firm for the given variable and then average those values for firms lying in the four sets. Similarly, we find the average standard deviation by first finding the standard deviation of the individual firm for the given variable and then averaging those values for firms lying in the four sets which are electronic industry, food industry, category-1, and category-2 firms.

\subsection{Average Sales Value}

From Table 5 we can see that average standard deviation is less than the mean for all the four sets. Though, the average sales value for food industry firms is higher than electronic industry firms, the value of average standard deviation is higher for the former. Average sales value is higher for category-2 firms.

Table-5. Descriptive statistics of average sales value (2008-2017) (INR Million).

\begin{tabular}{c|c|c|c|c}
\hline Variables & Electronic Ind. & Food Ind. & Category-1 & Category-2 \\
\hline Maximum & 88487.28 & 54733.54 & 29443.52 & 88487.28 \\
\hline Minimum & 0.54 & 2 & 0.54 & 2 \\
\hline Mean & 3204.26 & 4394.13 & 3669.45 & 3850.79 \\
\hline Av.Std.Deviation & 1357.64 & 2014.54 & 1685.19 & 1680.13 \\
\hline
\end{tabular}

\subsection{Average Total Assets}

From Table 6 we infer that there is not much noise in the data as mean is higher than the standard deviation for all the four sets. Average total assets for electronic industry firms are higher than that for food industry firms whereas for category-2 firms are higher than that for category-1 firms.

Table-6. Descriptive statistics of average total assets (2008-2017) (INR Million).

\begin{tabular}{c|c|c|c|c}
\hline Variables & Electronic Ind. & Food Ind. & Category-1 & Category-2 \\
\hline Maximum & 61613.92 & 30213.62 & 18482.52 & 61613.92 \\
\hline Minimum & 3.7 & 12.49 & 3.7 & 4.8 \\
\hline Mean & 4134.847 & 2756.246 & 3171.425 & 3592.475 \\
\hline Av.Std.Deviation & 1708.289 & 1038.016 & 1113.811 & 1505.989 \\
\hline
\end{tabular}




\subsection{Cost of Manufacturing and Sales}

We can see from Table 7 that the mean of average cost of sales and manufacturing for category-1 and category-2 is almost the same. Surprisingly, the mean of average costs is more for food industry than electronic industry firms, though the standard deviation is higher for the latter.

\begin{tabular}{c|c|c|c|c}
\multicolumn{2}{c}{ Table-7. Descriptive statistics of cost of manufacturing and sales (2008-2017) (INR Million). } \\
\hline Variables & Electronic Ind. & Food Ind. & Category-1 & Category-2 \\
\hline Maximum & 75502.750 & 50322.920 & 28897.650 & 75502.750 \\
\hline Minimum & 0.467 & 1.8334 & 0.4667 & 1.834 \\
\hline Mean & 3047.635 & 4302.982 & 3613.107 & 3693.374 \\
\hline Av.Std.Deviation & 1188.012 & 1789.983 & 1468.975 & 1492.885 \\
\hline
\end{tabular}

1.6. Compensation to Employees (COE) as a Percent of a Firm's Sales Revenue and Change in Stock

The ratio analyzes the expense on compensation to employees (COE) as a percent of a firm's sales revenue. Table 8 raises some concerns as the mean values are less than the standard deviation for all the four sets which indicates that there is some noise in the data. It also questions the variability in the returns employees receive in different industries.

Table-8. Descriptive statistics of COE as a percent of sales and change in stock (2008-2017) (\%).

\begin{tabular}{c|c|c|c|c}
\hline \multicolumn{2}{c}{ Table-8. Descriptive statistics of $\mathrm{COE}$ as a percent of sales and change in stock $(2008-2017)(\%)}$. \\
\hline Maximum & Electronic Ind. & Food Ind. & Category-1 & Category-2 \\
\hline Minimum & 1371.971 & 1230.308 & 1230.308 & 1371.971 \\
\hline Mean & -94.2862 & -11.89047 & -11.89047 & -94.2862 \\
\hline Av.Std.Deviation & 67.082 & 25.63903 & 43.73634 & 32.97736 \\
\hline
\end{tabular}

\subsection{Cost of Raw Material, Stores and Spares as a Percent of Sales and Change in Stock}

Table 9 gives descriptive statistics of raw material, stores and spares as a percent of sales and change in stock. This data reflects how much of sales revenue are utilized in the absorption of its costs incurred on raw materials, stores and spares. It is part of variable cost of a company. These costs on average are more for category- 1 firms as compared to category- 2 firms. One plausible reason is that changing product line requires additional cost in terms of purchasing new raw materials and required materials, though the standard deviation is also very high for the former indicating a large noise in the data. Counterintuitively, the average costs are higher for food than electronic industry firms. Again, the standard deviation is also high implying that the data is spread out. We test the difference in the means in the next section.

\begin{tabular}{c|c|c|c|c}
\multicolumn{2}{c}{ Table-9. Descriptive statistics of raw material, stores and spares as a percent of sales and change in stock $(2008-2017)(\%)$} \\
\hline Variables & Electronic Ind. & Food Ind. & Category-1 & Category-2 \\
\hline Maximum & 1428.031 & 3778.233 & 3778.233 & 1428.031 \\
\hline Minimum & -311.6334 & 0 & 0 & -311.633 \\
\hline Mean & 60.006 & 106.0497 & 134.655 & 57.436 \\
\hline Av.Std.Deviation & 51.714 & 112.876 & 173.832 & 37.120 \\
\hline
\end{tabular}

\section{Means Test}

We test whether the difference in the means for variables of average size, expenditure on advertisement, compensation to employees, and raw material, and profit measures like PBIDTA and PAT are significant using Mann-Whitney U test, sometimes called Wilcoxon Rank-Sum test or Mann-Whitney-Wilcoxon test. It is a nonparametric test used to test whether two independent samples are derived from same population. It does not require the assumption of normal distribution and is nearly as efficient as the t-test on normal distribution.

The null and two-sided research hypotheses for the nonparametric test are stated as follows: $\mathrm{H}_{\mathrm{o}}$ : The two populations are equal.

$\mathrm{H}_{1}$ : The two populations are not equal i.e. the population distributions are different in some way, center, spread and/or shape. Rejecting null hypothesis is interpreted to mean that one of the populations tend to have larger scores than the other.

As we have seen from the descriptive statistics that the measures of different variables have shown large noise and high skewness, the amount of information that the mean contains is questionable. We find the statistical significance in the means in the following section.

\subsection{Size of the Firm}

Size here is defined as the three-year average of the total income and total assets of a firm. Average size is larger for electronic industry though the difference is not statistically significant. Table 10 shows average size of category-1 firms is slightly higher though the difference is not statistically significant and Table 11 shows that average size of category-1 firms is slightly higher and the difference in the two distributions is significant at 10 percent level of significance ${ }^{2}$.

For all the statistics hereafter the value for individual firm is found by averaging the values from years 2008 to 2017 unless otherwise. 
Table-10. Mean of size of firm (Industry-wise).

\begin{tabular}{c|c|c|l}
\hline Variables & Size (INR Million) & $\mathbf{z}, \mathbf{p}$-value & Inference \\
\hline Electronic & 3367.560 & $\mathrm{z}=-1.170$ \\
Food & 3129.373 & $\begin{array}{l}H_{o} \text { is not rejected. } \\
\text { Difference in the means is } \\
\text { not statistically significant }\end{array}$ \\
\hline
\end{tabular}

Table-1 1. Mean of size of firm (Category-wise).

\begin{tabular}{c|c|c|l}
\hline \multicolumn{4}{|c}{ Table-11. Mean of size of firm (Category-wise). } \\
\hline Variables & Size (INR Million) & $\mathbf{z}, \mathbf{p}$-value & Inference \\
\hline Category-1 & 3259.975 & $\mathrm{z}=-1.756$ \\
Category-2 & 3245.181 & $\begin{array}{l}H_{o} \text { is rejected at } 10 \% . \\
\text { Difference in the means is } \\
\text { statistically significant }\end{array}$ \\
\hline
\end{tabular}

\subsection{Advertising Expense as a Percent of Sales and Change in Stock}

The ratio serves as an indicator of a company's profitability, by analyzing the magnitude of the company's sales revenue spent on advertising cost. Table 12 shows that for firms in food industry, average advertising cost is higher than electronic industry firms. In Table 13 it is shown that the same ratio for category-2 firms is higher than for category-1 firm, even though both are not statistically different from each other.

Table-12. Mean of advertisement cost of firm (Industry-wise).

\begin{tabular}{c|c|c|l}
\multicolumn{4}{|c}{ Table-12. Mean of advertisement cost of firm (Industry-wise). } \\
\hline Variables & Adv./Sales $+\Delta$ Stocks $(\%)$ & p-value & Inference \\
\hline Electronic & 0.320 & $\mathrm{z}=-0.478$ \\
Prob $>|\mathrm{z}|=0.633$ & $\begin{array}{l}H_{o} \text { is not rejected. } \\
\text { Difference in the means is } \\
\text { not statistically significant }\end{array}$ \\
\hline
\end{tabular}

Table-13. Mean of advertisement cost of firm (Category-wise).

\begin{tabular}{|c|c|c|c|}
\hline Variables & Adv./Sales $+\Delta$ Stocks (\%) & p-value & Inference \\
\hline Category-1 & 0.444 & \multirow{2}{*}{$\begin{array}{c}\mathrm{z}=-0.869 \\
\text { Prob }>|\mathrm{z}|=0.385\end{array}$} & \multirow{2}{*}{$\begin{array}{l}H_{o} \text { is not rejected. } \\
\text { Difference in the means is } \\
\text { not statistically significant }\end{array}$} \\
\hline Category-2 & 0.827 & & \\
\hline
\end{tabular}

2.3. Compensation to Employees as a Percent of Sales and Change in Stock

From Table 14 it can be seen that COE as a percent of sales is higher for electronic industry firms and the null hypothesis of no difference in population is rejected at 1 percent level of significance. Whereas for category-1 firms it is higher but the two sets of distributions are not statistically different from each other seen in Table 15 .

\begin{tabular}{c|c|c|l}
\multicolumn{5}{|c}{ Table-14. Mean of compensation to employees of firm (Industry-wise). } \\
\hline Variables & COE/Sales $+\Delta$ Stocks $(\%)$ & $\mathbf{z}, \mathbf{p}$-value & Inference \\
\hline Electronic & 47.082 & $\mathrm{z}=4.001$ & $\begin{array}{l}H_{o} \text { is rejected at } 1 \% . \\
\text { Prob }>|\mathrm{z}| \\
\end{array}$ \\
\hline Food & 25.639 & $\begin{array}{l}\text { Difference in the means is } \\
\text { statistically significant }\end{array}$ \\
\hline
\end{tabular}

Table-15. Descriptive statistics of compensation to employees of firm (Category-wise)

\begin{tabular}{|c|c|c|c|}
\hline Variables & COE/Sales $+\Delta$ Stocks (\%) & z, p-value & Inference \\
\hline Category-1 & 43.736 & \multirow[t]{2}{*}{$\begin{array}{c}z=0.706 \\
\text { Prob }>|z|=0.480\end{array}$} & \multirow{2}{*}{$\begin{array}{l}H_{o} \text { is not rejected. } \\
\text { Difference in the means is } \\
\text { not statistically significant }\end{array}$} \\
\hline Category-2 & 32.977 & & \\
\hline
\end{tabular}

\subsection{Raw Material, Stores and Spares as a Percent of Sales and Change in Stock}

Table 16 and Table 17 respectively show that for electronic industry firms the ratio is higher and the difference between the two groups is significant at 5 percent level of significance whereas for category 1 and 2 the difference is not significant.

\begin{tabular}{c|c|c|l}
\multicolumn{4}{c}{ Table-16. Mean of raw material, stores and spares cost of firm (Industry-wise). } \\
\hline Variables & Raw/Sales $+\Delta$ Stocks $(\%)$ & $\mathbf{z}, \mathbf{p}$-value & Inference \\
\hline Electronic & 49.870 & $\mathrm{z}=-2.102$ & $\begin{array}{l}H_{o} \text { is rejected at } 5 \% . \\
\text { Difference in the means is } \\
\text { statistically significant }\end{array}$ \\
\hline Food & 54.232 & Prob $>|\mathrm{z}|=0.036^{*}$ & \begin{tabular}{l} 
is \\
\hline
\end{tabular}
\end{tabular}

\begin{tabular}{|c|c|c|c|}
\hline Variables & Raw/Sales $+\Delta$ Stocks (\%) & p-value & Inference \\
\hline$\overline{\text { Category-1 }}$ & 50.910 & \multirow{2}{*}{$\begin{array}{c}\mathrm{z}=0.012 \\
\text { Prob }>|\mathrm{z}|=0.991\end{array}$} & \multirow{2}{*}{$\begin{array}{l}H_{o} \text { is not rejected. } \\
\text { Difference in the means is } \\
\text { not statistically significant }\end{array}$} \\
\hline Category-2 & 52.564 & & \\
\hline
\end{tabular}

\subsection{Pat as a Percent of Net Worth}

PAT is profit after tax. PAT/Net worth is a measure of returns over investment. This measure is commonly known as return on equity (ROE). Net worth is the sum of funds provided by equity shareholders and accumulated reserves of a firm. Higher the ratio, the more efficient the management is in utilizing its equity base. Average of 
ROE is higher for electronic industry firms and category-1 firms. Both the results are statistically insignificant and are given in Table 18 and Table 19 respectively.

Table-18. Mean of REO of firms (Industry-wise).

\begin{tabular}{|c|c|c|c|}
\hline Variables & PAT/Net worth (\%) & z, p-value & Inference \\
\hline Electronic & 1.317 & \multirow[t]{2}{*}{$\begin{array}{c}\mathrm{z}=-1.079 \\
\text { Prob }>|\mathrm{z}|=0.281\end{array}$} & \multirow{2}{*}{$\begin{array}{l}H_{o} \text { is not rejected. } \\
\text { Difference in the means is } \\
\text { not statistically significant }\end{array}$} \\
\hline Food & -0.967 & & \\
\hline \multicolumn{4}{|c|}{ Table-19. Mean of REO of firms (Category-wise). } \\
\hline Variables & PAT/Net worth (\%) & z, p-value & Inference \\
\hline Category-1 & 4.516 & \multirow{2}{*}{$\begin{array}{c}z=0.662 \\
\text { Prob }>|z|=0.508\end{array}$} & \multirow{2}{*}{$\begin{array}{l}H_{o} \text { is not rejected. } \\
\text { Difference in the means is } \\
\text { not statistically significant }\end{array}$} \\
\hline Category-2 & -2.025 & & \\
\hline
\end{tabular}

\subsection{Pbidta as a Percent of Total Income}

This is a ratio of profitability of total income of a firm. PBIDTA is profits before depreciation, interest, tax and amortization. It is a measure of operating profits. Higher PBIDTA as a percentage of total income indicates that a company is generating good profits from its day-to-day business operations. As indicated from Table 20 PBIDTA/Total income measure for electronic industry firms is very less as compared to food industry firms and the difference statistically significant at 1 percent level of significance. Difference for firms in category 1 and 2 is not statistically significant which is given in Table 21 .

Table-20. Mean of PBIDTA/total income of firms (Industry-wise).

\begin{tabular}{c|c|c|l}
\hline Variables & PBIDTA/Total income & $\mathbf{z}, \mathbf{p}$-value & Inference \\
\hline Electronic & -3.682 & $\mathrm{z}=3.597$ & $\begin{array}{l}H_{o} \text { is rejected at } 1 \% . \\
\text { Prob }>|\mathrm{z}|= \\
\text { Difference in the means is } \\
\text { statistically significant }\end{array}$ \\
\hline Food & 7.839 & .000*** & \\
\hline
\end{tabular}

Table-21. Mean of PBIDTA/total income of firms (Category-wise).

\begin{tabular}{c|c|c|l}
\hline Variables & PAT/Net worth $\mathbf{( \% )}$ & $\mathbf{z}, \mathbf{p}$-value & Inference \\
\hline Category-1 & 10.716 & $\mathrm{z}=-0.321$ \\
Category-2 & -2.240 & $\begin{array}{l}H_{o} \text { is not rejected. } \\
\text { Difference in the means is } \\
\text { not statistically significant }\end{array}$ \\
\hline
\end{tabular}

\section{Appendix 2}

The strategy of a product line change is not an exogenous strategy and depends on a firm's characteristics therefore we have used difference-in-differences analysis. In this section we represent an alternative result by assuming that the strategy of product line change was like an exogenous treatment. This is a big assumption which is difficult to fulfill hence we give the results in the appendix just to show how the average sales value differ between firms changing product line and firms not changing product line for the two industries separately. We first explain the average treatment effect using propensity score matching and then report the results.

\section{Propensity Score Matching}

Propensity score matching (PSM) is a statistical matching technique popularly used to estimate causal treatment effects. It applies to all situations where we define a treatment and can form two groups; one with treated individuals and the other with untreated individuals (Caliendo and Kopeinig, 2005). One would like to know the difference in the outcome of treated without the treatment. Let the dummy for a binary treatment be denoted by $T_{i}$ for individual $\mathrm{i}$, be equal to one if the individual receives a treatment and zero otherwise. The potential outcome for each individual can be denoted by $Z_{i}\left(T_{i}\right)$. The treatment effect is then $\left[Z_{i}(1)-Z_{i}(0)\right]$ for each individual. The problem arises because both the outcomes are not observable for each individual. Therefore we cannot find individual treatment effect and have to work on average treatment effect. Another measure of interest is the average treatment effect on the treated. This is defined as:

ATET $=\mathrm{E}($ Treatment $\mid \mathrm{T}=1)=\mathrm{E}[\mathrm{Z}(1) \mid \mathrm{T}=1]-\mathrm{E}[\mathrm{Z}(0) \mid \mathrm{T}=1]$

The problem in finding ATET is that $(\mathrm{E}[\mathrm{Z}(0) \mid \mathrm{T}=1])$ is not observable. Substituting the missing value by the average outcome of untreated individuals is not a good idea as in non-experimental studies the conditions under which the decision of treatment is taken may also influence the potential outcome. Hence the two groups may possibly be different even in the absence of the treatment. This is called 'self-selection bias'. One strategy is to compare the outcome of those individuals in the group who have similar covariates which influence the outcome. For instance, if age affects both treatment selection and outcome, one would compare individuals of similar age in both groups. As variables are added to the matching process, it becomes more complex to find exact matches. PSM provides a way to balance covariates across treatment and control groups and better approximate the counterfactual for treated individuals. It solves the problem by compressing the relevant factors into a single score. We find the propensity scores which is the probability for an individual to participate in the treatment given the covariates i.e. $\mathrm{P}(\mathrm{T}=1 \mid \mathrm{X})=\mathrm{P}(\mathrm{X})$, it is one of the balancing scores (Rosenbaum and Rubin, 1983). Individuals with similar propensity scores are then compared across treatment and comparison groups.

Assumptions: 
One assumption is Conditional Independence Assumption (CIA) which requires that potential outcome be independent of treatment given the propensity scores. Other assumption called the Common Support Assumption (CSA) requires that an individual with same $\mathrm{X}$ have a positive probability of being a participant or non-participant.

Given CIA and CSA, propensity score estimator for ATET can be written as:

$$
\mathrm{ATET}_{\mathrm{PSM}}=\mathrm{E}_{\mathrm{P}(\mathrm{X}) \mid \mathrm{T}=1}\{\mathrm{E}[\mathrm{Z}(1) \mid \mathrm{T}=1, \mathrm{P}(\mathrm{X})]-\mathrm{E}[\mathrm{Z}(0) \mid \mathrm{T}=0, \mathrm{P}(\mathrm{X})]\}
$$

PSM estimator is the mean difference in outcomes over the common support, weighted by the propensity scores of individuals who are participating. Variables which simultaneously determine participation decision and outcome variables should be chosen as covariates. Variables should either be fixed over time or measured before participation to ensure that the covariates are not influenced by participation. For the implementation of ATET it is important to check the overlap and region of common support between the control and the treatment group.

In our analysis we find the average treatment effect on the treated (ATET) using propensity scores. We conduct the exercise for electronic and food industry firms separately and report the results below.

Result

We have the presence of category-1 and category- 2 firms in both food and electronic industry. We find the ATET by propensity score matching for both the industries separately. We would be interested to know what their average sales value would be had they not changed the product line, since we do not have that value we find the average sales value of the untreated firms which are similar to the treated firms in terms of average of total assets, average of cost of sales and manufacturing, PBIDTA/total income and PAT/net worth which is also the return on equity of a firm. Since the data on these covariates for firms were missing for most of the years from 2000-2007, we use the average values from year 2008-2017. Also from descriptive statistics it can be seen that category-1 and category-2 firms do not statistically differ for average PBIDTA/total income and PAT/net worth. Figure 6 and 7 Appendix 3 show the graph for before matching and after matching of the covariates for electronic industry firms and Figure 8 and 9 Appendix 3 show the same for food industry firms. The result for electronic and food industries are as follows:

Table-22. ATET for electronic industry firm.

\begin{tabular}{c|c|c|c|c|c|c}
\hline Variables & Coefficient & Robust Std. Error & $\mathbf{Z}$ & $\mathbf{P}>|\mathbf{z}|$ & \multicolumn{2}{|c|}{$[\mathbf{9 5 \%}$ Confidence Interval] } \\
\hline (Treated Vs Untreated) & 0.862 & 0.446 & 1.93 & $0.053^{*}$ & -0.125 & 1.736 \\
\hline
\end{tabular}

Table-23. ATET for food industry firm.

\begin{tabular}{|c|c|c|c|c|c|c|}
\hline Variables & Coefficient & Robust Std. Error & $\mathbf{Z}$ & $\mathbf{P}>|\mathbf{z}|$ & {$[95 \%$} & e Interval] \\
\hline (Treated Vs Untreated) & -0.415 & 0.309 & -1.34 & 0.180 & -1.021 & 0.191 \\
\hline
\end{tabular}

From Table 22 it can be inferred that treated firms are earning 82.6 percent more than the untreated firms of similar covariates and the result is significant at 10 percent level of significance. For the food industry firms on the other hand the treated firms do worse on average though the result is not statistically significant which is given in Table 23.

Thus we can claim that product line change is an important strategy for electronic industry firms. There can be various reasons for this but an important reason is the characteristic of the products the industry produces. The goods are more durable and are technologically intensive. Technology keeps on changing, so it is crucial for these firms to reinvent themselves. Also since the consumers keep the goods for a relatively longer period of time, the firms face an additional self-created competition. It is important note that the inference from the result maybe questionable because of the big assumption. This analysis only hints at the situation in which product line change is an exogenous treatment for firms.

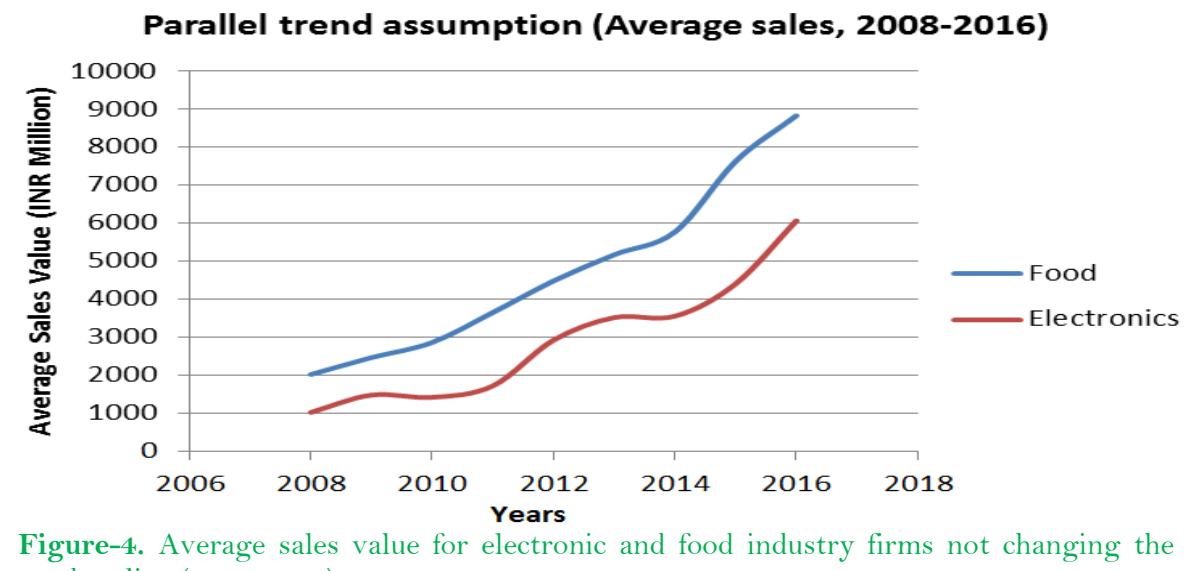
product line (2008-2016). 


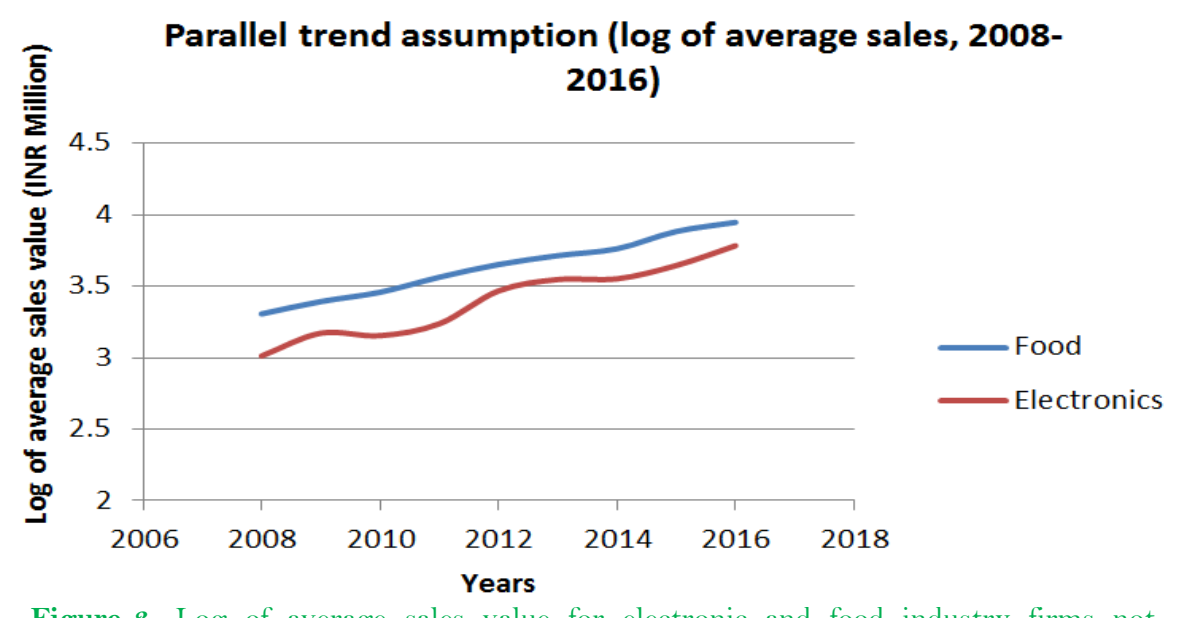

Figure-3. Log of average sales value for electronic and food industry firms not changing the product line (2008-2016).

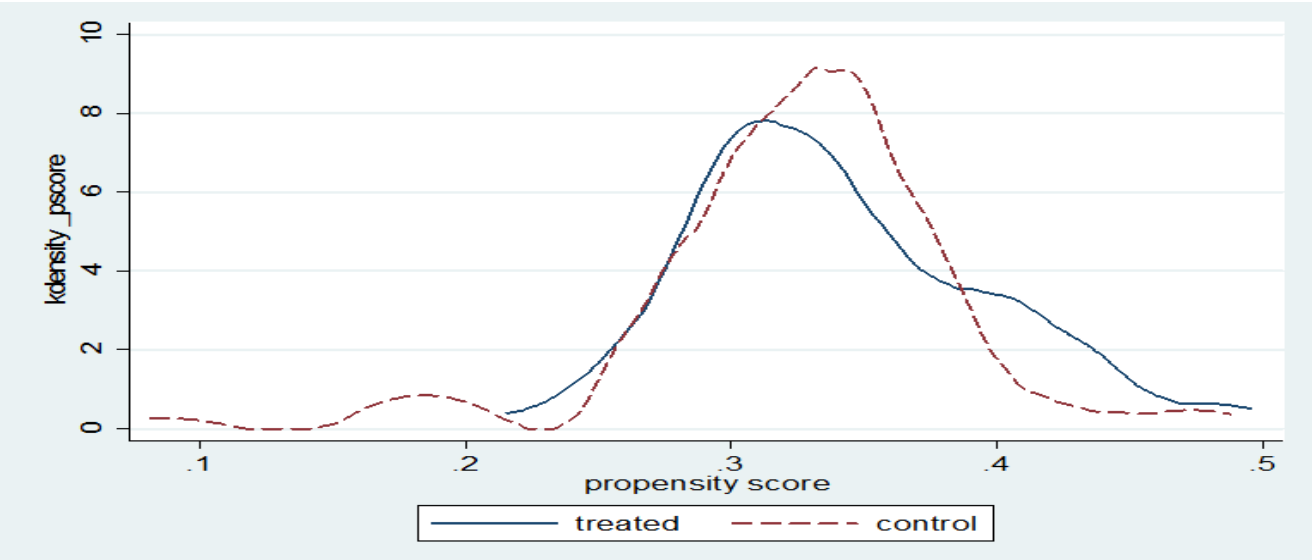

Figure-4. Graph for propensity scores before matching for electronic industry firm.

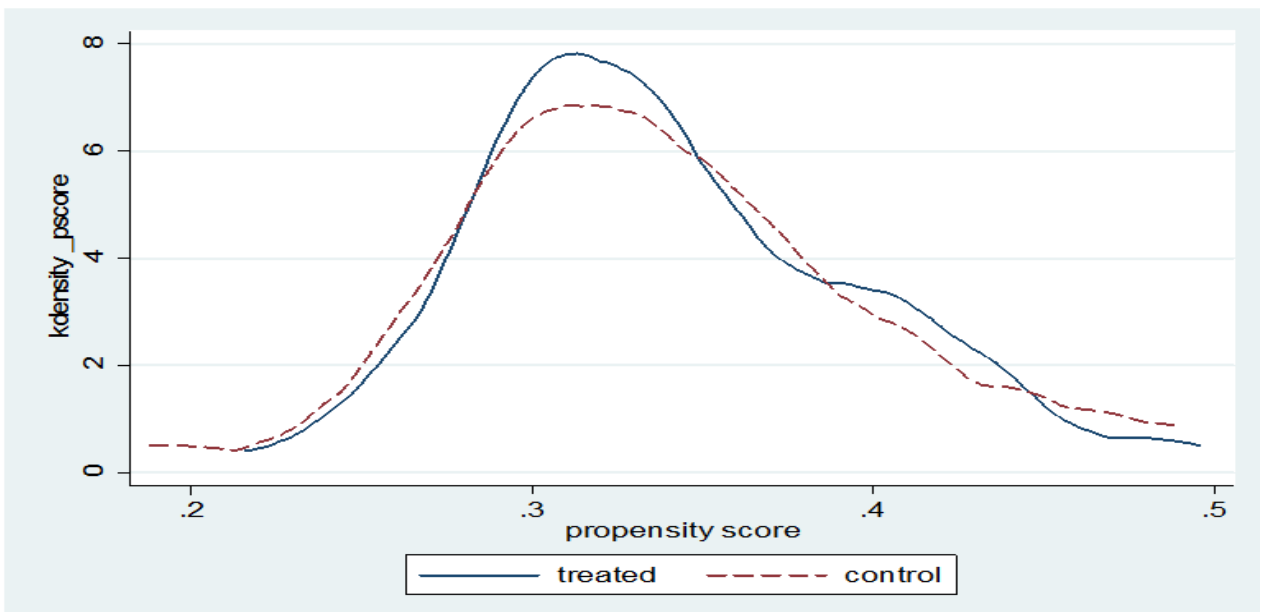

Figure-5. Graph for propensity scores after matching for electronic industry firm.

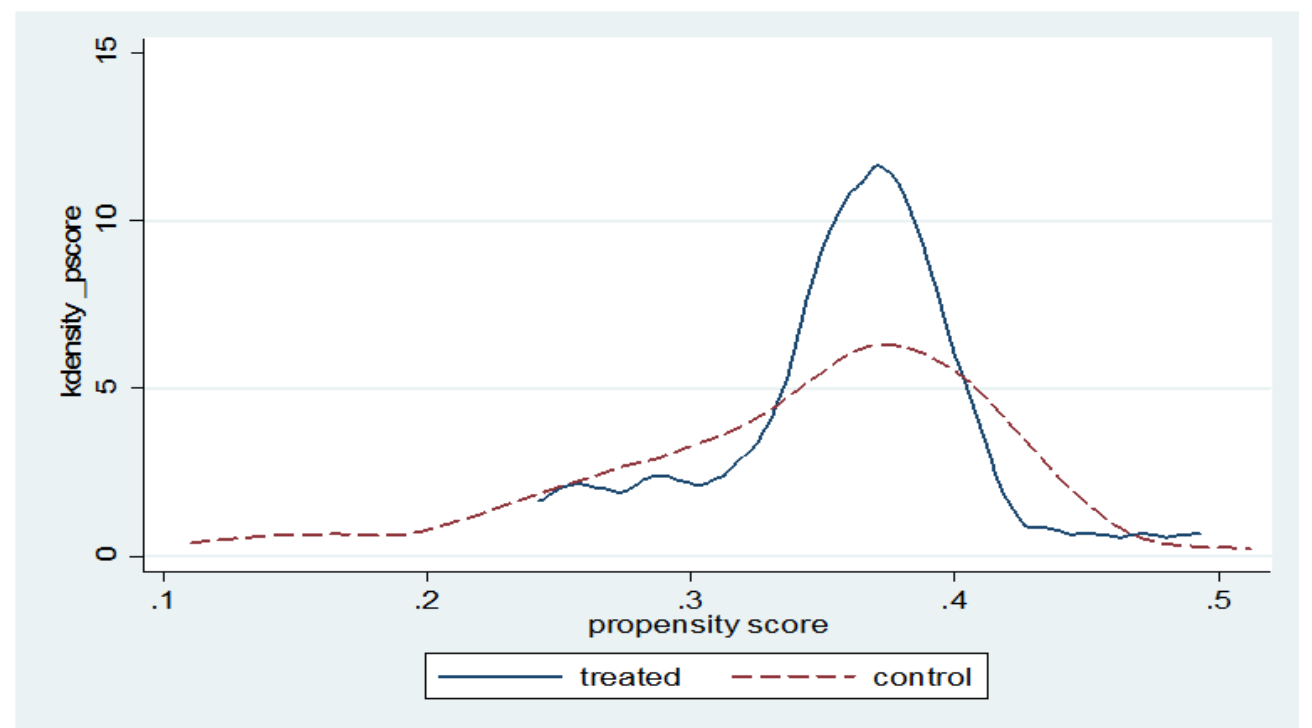

Figure-8. Graph for propensity scores before matching for food industry firm. 


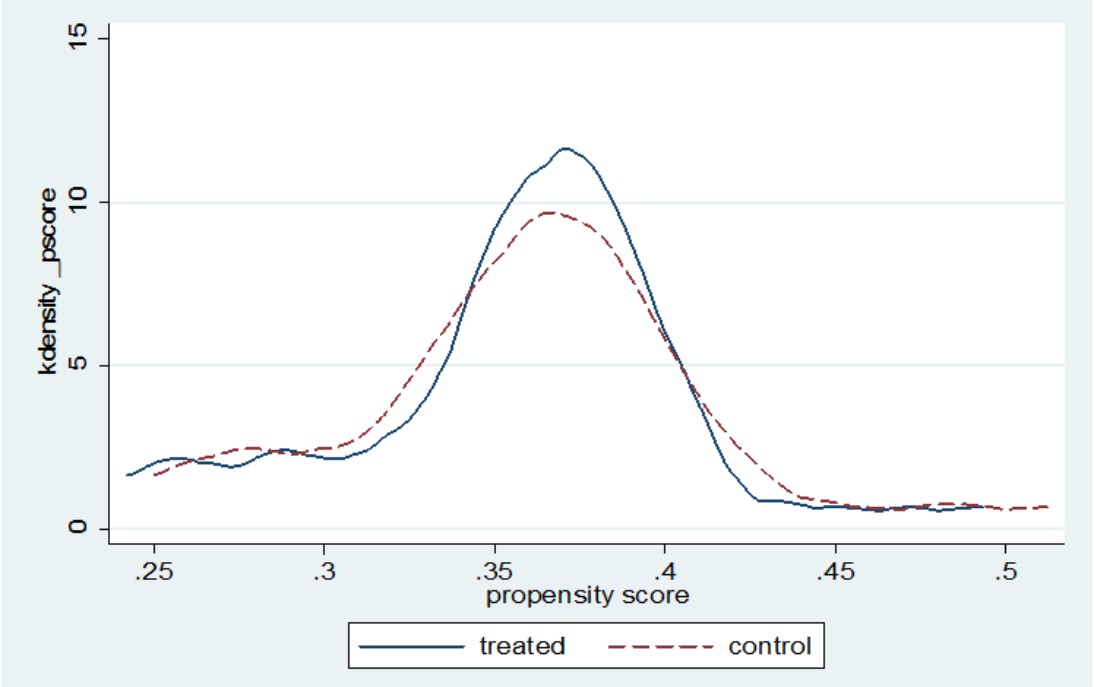

Figure-9. Graph for propensity scores after matching for food industry firm. 